\title{
AC DIRECT DRIVE LED LIGHTING USING LOW-COST ANALOG COMPONENTS
}

\author{
A Thesis \\ presented to \\ the Faculty of California Polytechnic State University, \\ San Luis Obispo
}

\author{
In Partial Fulfillment \\ of the Requirements for the Degree \\ Master of Science in Electrical Engineering
}

by

Miles Head

May 2019 
(C) 2019

Miles Davis Head

ALL RIGHTS RESERVED 
COMMITTEE MEMBERSHIP

TITLE: $\quad$ AC Direct Drive LED Lighting Using Low-Cost Analog Components

AUTHOR: $\quad$ Miles Head

DATE SUBMITTED: $\quad$ May 2019

COMMITTEE CHAIR: Taufik, Ph.D.

Professor of Electrical Engineering

COMMITTEE MEMBER: $\quad$ Ahmad Nafisi, Ph.D.

Professor of Electrical Engineering

COMMITTEE MEMBER: Majid Poshtan, Ph.D.

Professor of Electrical Engineering 


\author{
ABSTRACT \\ AC Direct Drive LED Lighting Using Low-Cost Analog Components \\ Miles Head
}

This project explores the rapidly expanding area of $A C$ direct drive for LED lighting. AC LED driving does not use typical DC-DC converter-based driving but uses semiconductor switches and a linear regulator to activate a number of LEDs proportional to the input voltage at any given time. This allows bulky, expensive magnetics to be eliminated from the system. The goal of this project was to design a scaled-down physical AC LED direct drive system to validate the conclusions of methods for improving efficiency from a previous investigation that found minimizing voltage across the linear regulating MOSFET led to higher efficiency at the cost of increased input current THD. This project found that this conclusion is physically realizable, with a final efficiency of $94.46 \%$ and an input current THD of $58.9 \%$. This result was achieved by taking the previous investigation's final design as a starting point and replacing ideal switches and control signals with discrete components. The final version uses a set of comparators and sense resistors to determine when a given LED stack should be on for a simple, analog control solution. Once the system was simulated this way, the assembled version was used to measure efficiency, power factor, current THD, flicker index, and DC supply power. Additional plots of the stack voltages and control signals were collected to verify proper operation and compare to simulation. The final measurements aligned with trends from simulation and result in a simple AC direct drive solution that requires no specialty ICs. 


\section{ACKNOWLEDGMENTS}

Thank you to my wonderfully supportive parents, friends, and family for believing in me and getting me through the last five years. 


\section{TABLE OF CONTENTS}

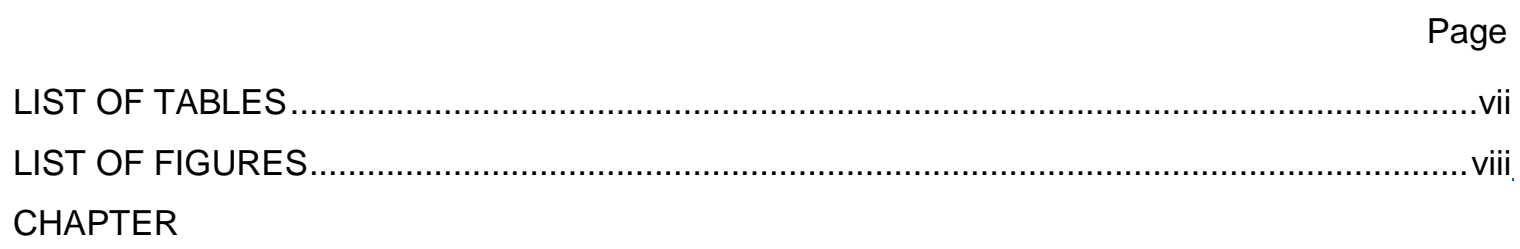

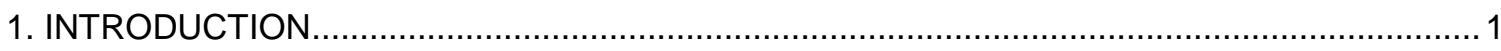

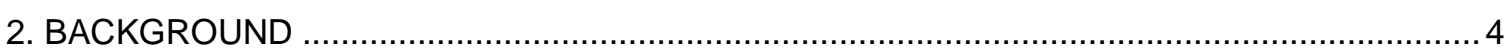

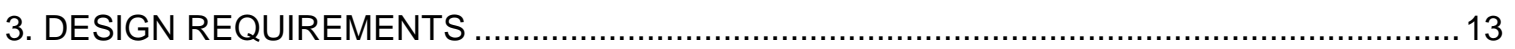

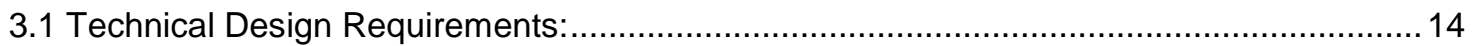

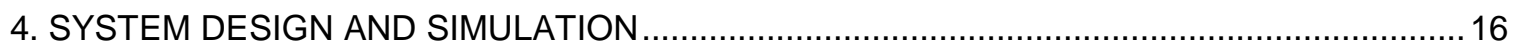

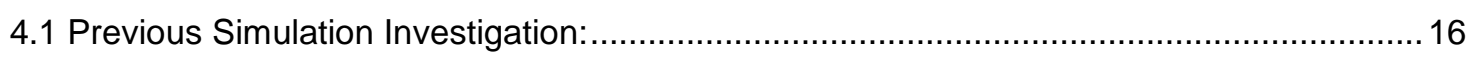

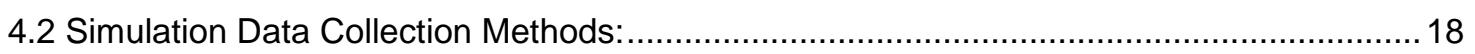

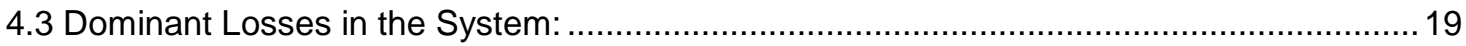

4.4 Previous Investigation: Five-Stack, Binary Custom Switching ........................................20

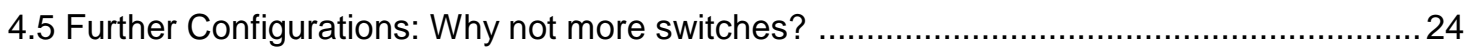

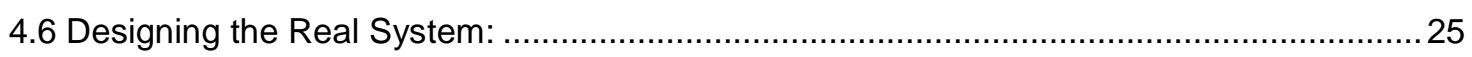

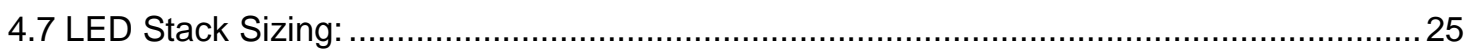

4.8 Switch and Switch Driver Choice:

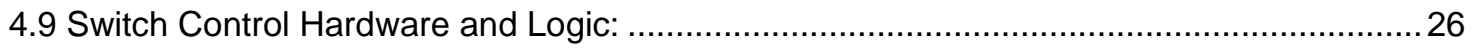

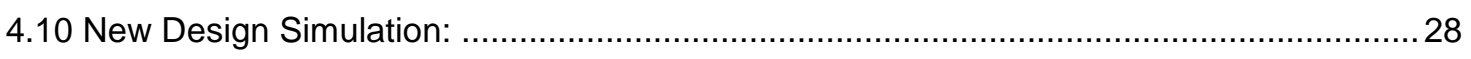

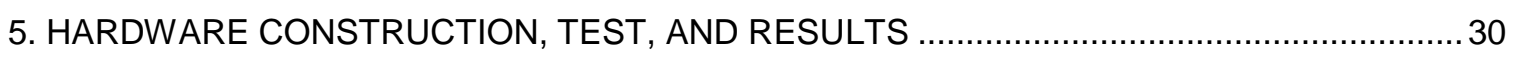

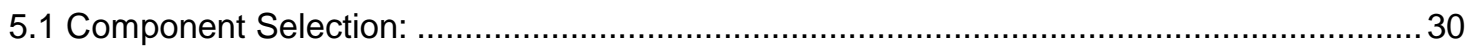

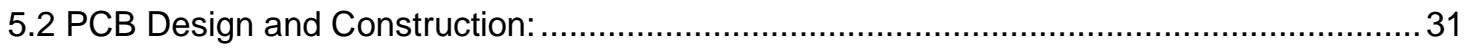

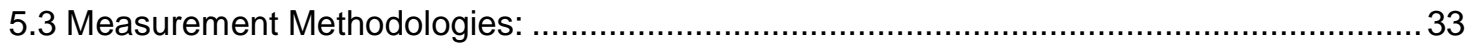

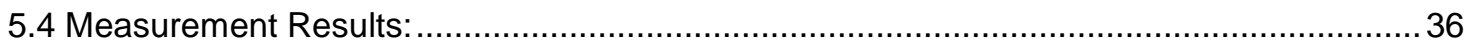

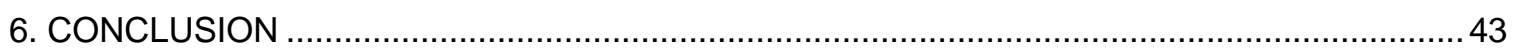

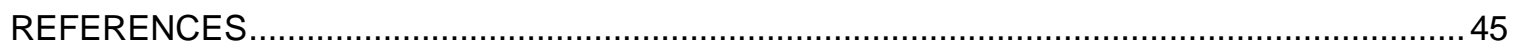

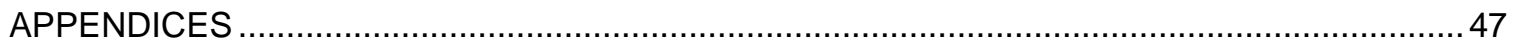

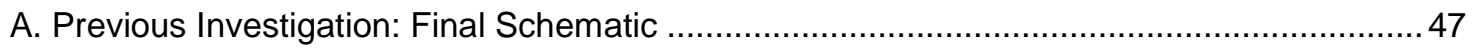

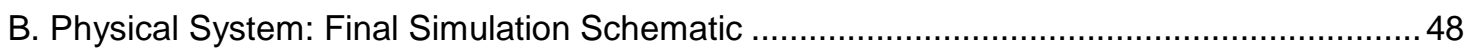

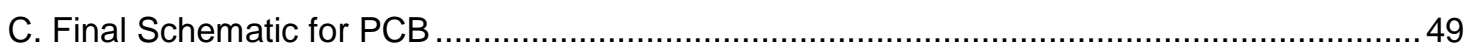

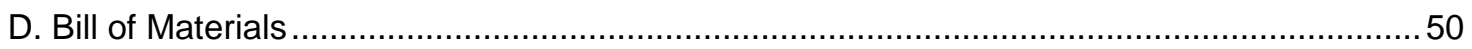

E. MATLAB Code used for Flicker Index Calculation: ........................................................ 52 


\section{LIST OF TABLES}

Table

2-1: A selection of projection data showing the expected growth of CFL technology in residential spaces [8].

2-2: A selection of projection showing the expected growth of LED bulbs in residential spaces [8].

2-3: LED stack count for each string according to Hwu's method [14].

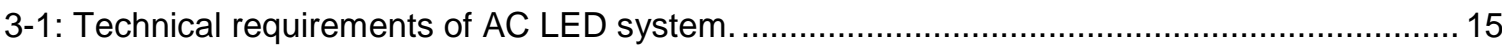

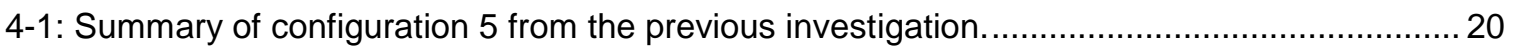

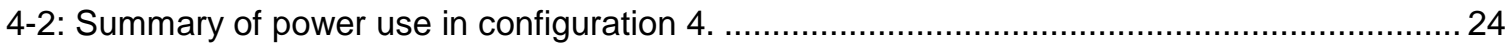

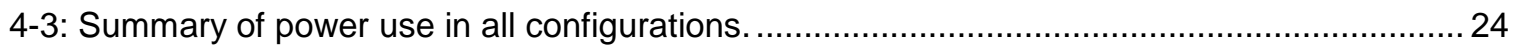

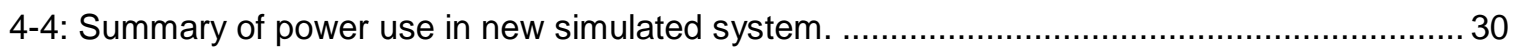

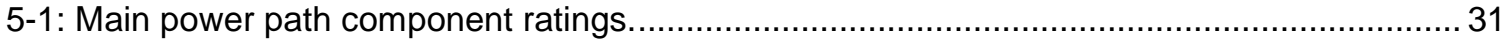

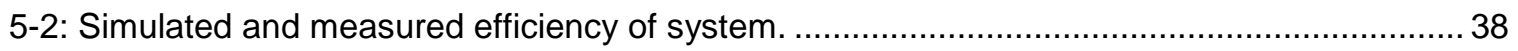

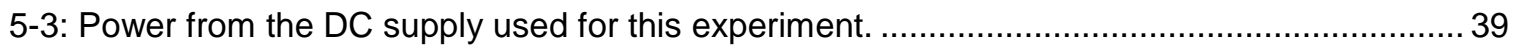

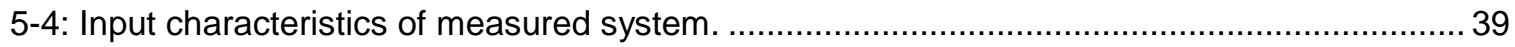




\section{LIST OF FIGURES}

Figure

Page

1-1. Energy consumption in the US by energy source [2] 1

1-2. Light bulb use by type in commercial applications, from US EIA study [6].......................... 3

2-1. A series switching system (top) and parallel switching system (bottom) [11] ....................... 6

2-2. Augmented diagram showing three switch states in a series configuration [11]................... 7

2-3. Hwu switch control method avoiding gate driving IC [14] .................................................

2-4. Block-level diagram of proposed system with binary counter [15]. ................................. 10

2-5. Representation of two ways to quantify flicker. ......................................................... 11

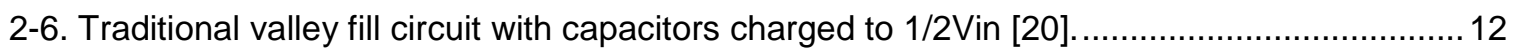

2-7. Proposed modified valley fill with capacitor charged to Vin [20]........................................ 12

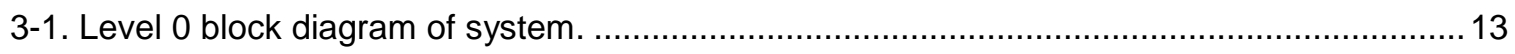

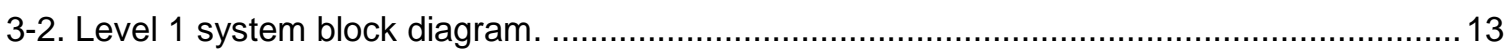

4-1. Example of a single voltage-controlled switch reading from a control file periodically..........17

4-2. Discrete linear regulator used for all testing. ............................................................ 17

4-3. Block diagram description of configuration 5 of the previous investigation. ..........................20

4-4. Example demonstrating where extra switch signals were added to improve beyond configuration 3 .

4-5. From top to bottom: Rectified input voltage and total stack voltage, switch signal one, switch signal two, switch signal three, switch signal four, switch signal five........................21

4-6. From top to bottom: voltage across stack one, two, three, four, five ................................... 22

4-7. From top to bottom: current through stack one, two, three, four, five................................... 22

4-8. From top to bottom: Rectified input voltage and total LED stack voltage, MOSFET drain-

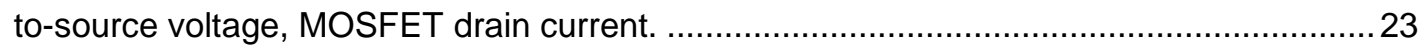

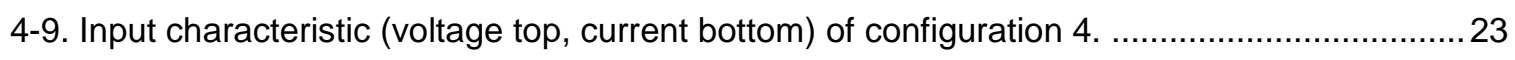

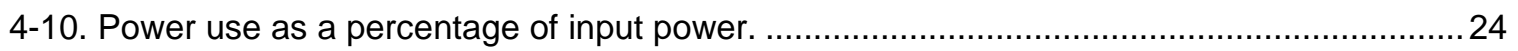

4-11. Switch and switch driver, N-type MOSFET is used to drive the base of a PNP transistor...26 
4-12. A generic version of the control circuitry for this AC LED solution.

4-13. New simulation switch signals. From top to bottom: rectified line voltage and total LED stack voltage, switch signal 1, switch signal 2, switch signal 3, switch signal 4, and switch signal 5. Note that switch signals are inverted logic (a low signal means that LED stack is on).

4-14. Stack voltages. From top to bottom: Rectified line voltage and total LED stack voltage, voltage across stack 1 , voltage across stack 2 , voltage across stack 3 , voltage across stack 4 , voltage across stack 5 .

4-15. Stack currents. From top to bottom: rectified line current, stack current 1, stack current 2, stack current 3 , stack current 4 , stack current 5.

4-16. Input voltage (top) and input current (bottom). 30

5-1. 3D rendering of final $\mathrm{PCB}$ design. 32

5-2. Populated PCB ready to be validated. .33

5-3. General lab bench setup for measurement of the system. .33

5-4. Output power measurement for each stack.

5-5. Application circuit for the OPT101 [24]. 35

5-6. Final flicker-measuring box. 35

5-7. Flicker measurement test setup .36

5-8. Measured LED control signals 37

5-9. Measured stack voltages. 37

5-10. Linear regulator MOSFET and resistor voltages. .38

5-11. Thermal image of the AC LED system during operation. 39

5-12. Output from flicker measuring tool used to calculate flicker index. .40

5-13. FFT of flicker signal obtained in the lab. 41

5-14. Portion of line/control waveforms under question (circled). 41

5-15. Line voltage and stack 1 voltage during short period of oscillation. .42

5-16. Line voltage and control voltage 1 during short period of oscillation. 42

5-17. Line voltage and sense voltage 1 during short period of oscillation. 42 


\section{Chapter 1 : INTRODUCTION}

Efficiency in energy usage is defined as a ratio of energy output to energy input. This definition holds true at a larger scale, when discussing energy use on a societal level. An energyefficient process is one that yields the same or more output for less energy input. It is important to separate energy efficiency from energy conservation. Energy conservation is usually abstaining from using energy for a process, rather than doing that process more efficiently [1]. One example of this would be working in a room that has natural sunlight instead of using a lamp. The lamp is not more efficient, it is simply used less.

Energy is created through many different processes, some of which are renewable and some which are not. A renewable energy source is "one that that can be easily replenished" [2], and a nonrenewable source is one that cannot. Some examples of nonrenewable sources include petroleum, natural gas, coal, and nuclear energy, whereas renewable sources include solar, geothermal, wind, and hydroelectric energy [2]. Since the majority of the United States' energy comes from nonrenewable sources (see Figure 1-1), using that limited energy efficiently is becoming more and more important. Use of renewable energy is increasing but in 2017 represented only $11 \%$ of energy consumption [2].

U.S. energy consumption by energy source, 2016

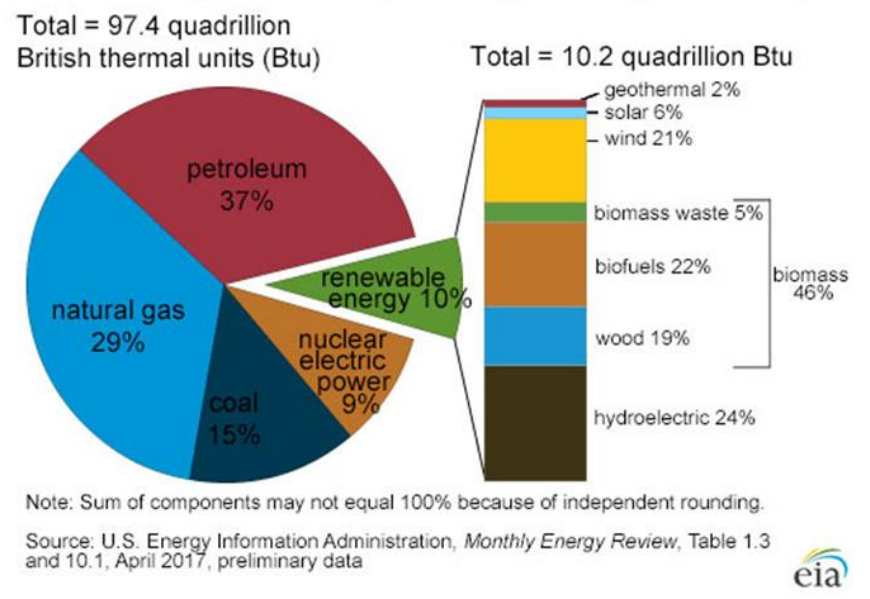

Figure 1-1: Energy consumption in the US by energy source [2]. 
Energy efficiency is a topic discussed often now, with continually growing concerns about climate change, as well as increased energy costs and shrinking nonrenewable reserves. Many homeowners, for example, improve their home's efficiency by upgrading windows, insulation, appliances, and/or lighting. Better insulation and windows help improve heat and air conditioning efficiency, and new appliances and lighting solutions increase electrical efficiency [1]. Some states have created energy efficiency resource standard plans (EERS) to reduce the growth of electricity consumption over time. These programs use financial incentives or non-performance penalties to encourage efficient energy use in the state [3]. These plans are usually updated, and goals are expanded as they are met.

One significant category of energy use is lighting. The US Energy Information Administration estimates that the residential and commercial sectors of the United States used 279 billion kilowatthours of electrical power for lighting in 2016 . That was $10 \%$ of the energy used in those sectors and $7 \%$ of the United States' total energy consumption [4]. The most popular lighting solutions are incandescent, fluorescent, compact fluorescent (CFL), and LED (light emitting diode). According to the US EIA, most households have a mix of these bulbs, where CFL and incandescent are the most popular [5]. In commercial buildings, over $90 \%$ of lighting is standard fluorescent, as seen in Figure 1-2. Also, in Figure 1-2, note that CFL use has increased over time and incandescent use has declined [6]. This is a common move from a less efficient to more efficient light bulbs to save energy and money. 


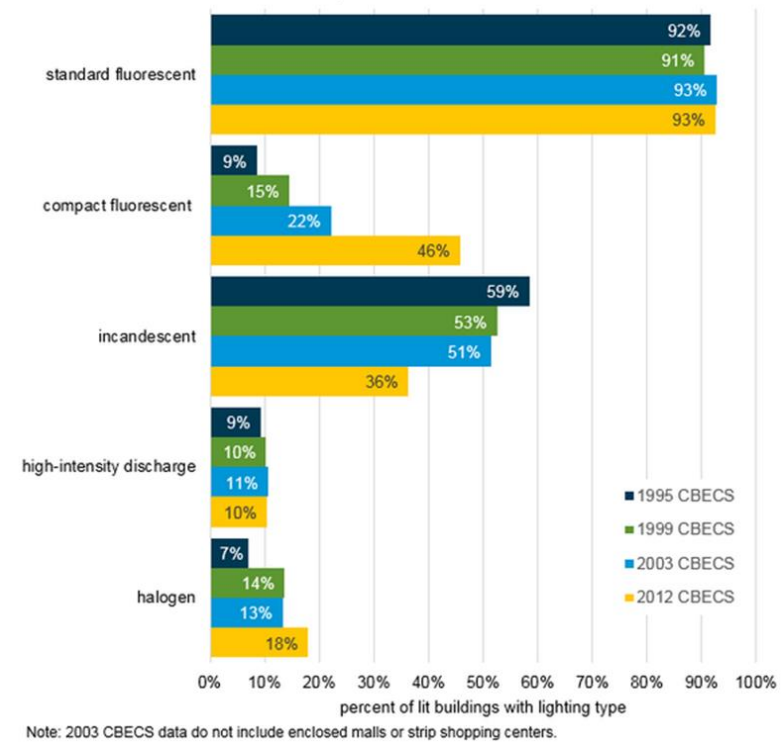

Figure 1-2: Light bulb use by type in commercial applications, from US EIA study [6].

Since 2013, LED bulb efficiency has exceeded typical CFL efficiency, with some exceeding 100 Lumens/Watt. Originally, LED bulbs were the most expensive but as prices come down, LED bulb shipments have increased from 9 million units in 2011 to 45 million units in 2013 [7]. If LED lighting solutions could be manufactured more simply, they could potentially become more widely used and help reduce energy use in residential and commercial settings. Since they have higher efficiency, diminishing prices, and longer lifetime, LED bulbs are becoming increasingly common option to save energy and money.

LED lighting is not without its drawbacks. Some examples exhibit flicker, similar to older fluorescent tubes, which can cause headaches in some people. This is due to the type of electronic driver used in the device. CFL bulbs typically have minimal flicker. Some drivers in LED lighting solutions can limit the lifespan of the device to less than the LEDs themselves. Despite these drawbacks, LEDs have advantages like adjustable color temperature, rapidly shrinking size for the diodes themselves, and even some flexible LED strips that can make for interesting lighting form factors. Also, as previously stated, they are generally more efficient than CFL solutions available [7]. LED is a lighting technology with room to mature and improve in quality, price and efficiency. 


\section{Chapter 2 : BACKGROUND}

The use of LEDs for lighting is a small proportion of residential lighting and an even smaller portion of commercial lighting, but the number of LED bulbs used is increasing [8]. Some legislation is encouraging the shift to LED. The Energy Independence and Security Act of 2007 (EISA 2007) raised efficiency standards for 60 -watt bulbs, effective in 2014, that incandescent bulbs could not meet. It is not expected that any company would attempt to make a more efficient incandescent bulb, since it is a mature technology with less room for growth than CFL or LED. EISA 2007 also set a minimum 45 lumens/watt efficiency standard effective in 2018 that is expected to eventually eliminate incandescent and halogen bulbs, forcing the market towards higher efficiency CFL and LED technologies [8]. In 2017, California's Title 24 will require household bulbs to exceed efficiency of $45 \mathrm{Im} /$ Watt, power factor of 0.9 , and rated life of 15,000 hours. These requirements will also push the market towards CFL and LED technologies [8].

Tables 2-1 and 2-2 show a selection of projection data on CFL and LED bulbs, respectively. These projections show that CFL bulbs, while efficient and inexpensive now, have less room to grow than LED bulbs. CFL efficiency, lifespan, and price are projected to improve much less than LED's. This demonstrates the expected push towards new LED technology and the need for innovation in the field to create these more efficient, longer lasting, and cheaper lighting solutions.

Table 2-1: A selection of projection data showing the expected growth of CFL technology in residential spaces [8].

\begin{tabular}{|c|c|c|}
\hline \multicolumn{2}{|c|}{ CFL Bulbs } \\
\hline & 2015 & $\mathbf{2 0 4 0}$ (projected) \\
\hline Efficiency (lumens/Watt) & 68.9 & 78.0 \\
\hline Typical Bulb Price & $\$ 2.03$ & $\$ 1.79$ \\
\hline Average life (1000 hours) & 10.0 & 11.3 \\
\hline
\end{tabular}


Table 2-2: A selection of projection showing the expected growth of LED bulbs in residential spaces [8].

\begin{tabular}{|c|c|c|}
\hline \multicolumn{2}{|c|}{ LED Bulbs } \\
\hline & 2015 & $\mathbf{2 0 4 0}$ (projected) \\
\hline Efficiency (lumens/Watt) & 93 & 161 \\
\hline Typical Bulb Price & $\$ 7.53$ & $\$ 2.00$ \\
\hline Average life (1000 hours) & 25 & 50 \\
\hline
\end{tabular}

Since LEDs operate with a DC current, most lighting solutions use an AC to DC converter to drive the LEDs. This can consist of a rectifier, followed by either a single stage with power factor correction (PFC) or two stages. These stages are switching DC to DC converters (such as a buck or boost) with large inductors and capacitors required. In a single stage solution, PFC maintains a good input characteristic with input current in phase with voltage, at the cost of larger flicker at the output, even with large filtering capacitors. A two-stage system has the first stage handling PFC, while the second reducing flicker, at the cost of adding a second stage. Large capacitors are still needed, as well as two inductors, which are a size issue in a bulb form factor [9]. Switching power supplies have the advantage of being very efficient, but the need for large electrolytic capacitors shortens the lifespan of the device. Even though LEDs and controllers have a lifespan of as much as 50,000 hours, the electrolytic capacitors have a much shorter life, which becomes the limiting factor of the device [9]. The size of capacitors and inductors/magnetics can be reduced by increasing the switching frequency of the system, but this in turn may degrade converter efficiency because of switching losses (which are proportional to switching frequency). Increasing frequency can also increase Electromagnetic Interference (EMI) noise. These aforementioned issues have driven researchers to find alternative methods to drive LEDs which better match the longevity of the devices and provide a simpler solution.

One such solution is referred to as AC direct drive of LEDs. In general, this method consists of using switches to control strings of LEDs and turning on a number of LEDs 
proportional to the input voltage at any given time. A linear regulator is typically used to dissipate any leftover voltage and it helps keep the input current in phase with the input voltage for improved power factor. A rectifier is still used at the input to have purely positive voltage swings into the system. This system is typically cheaper, simpler, and less noisy than DC to DC switching converters and the lack of input capacitors better matches system lifespan to LED lifespan [10].
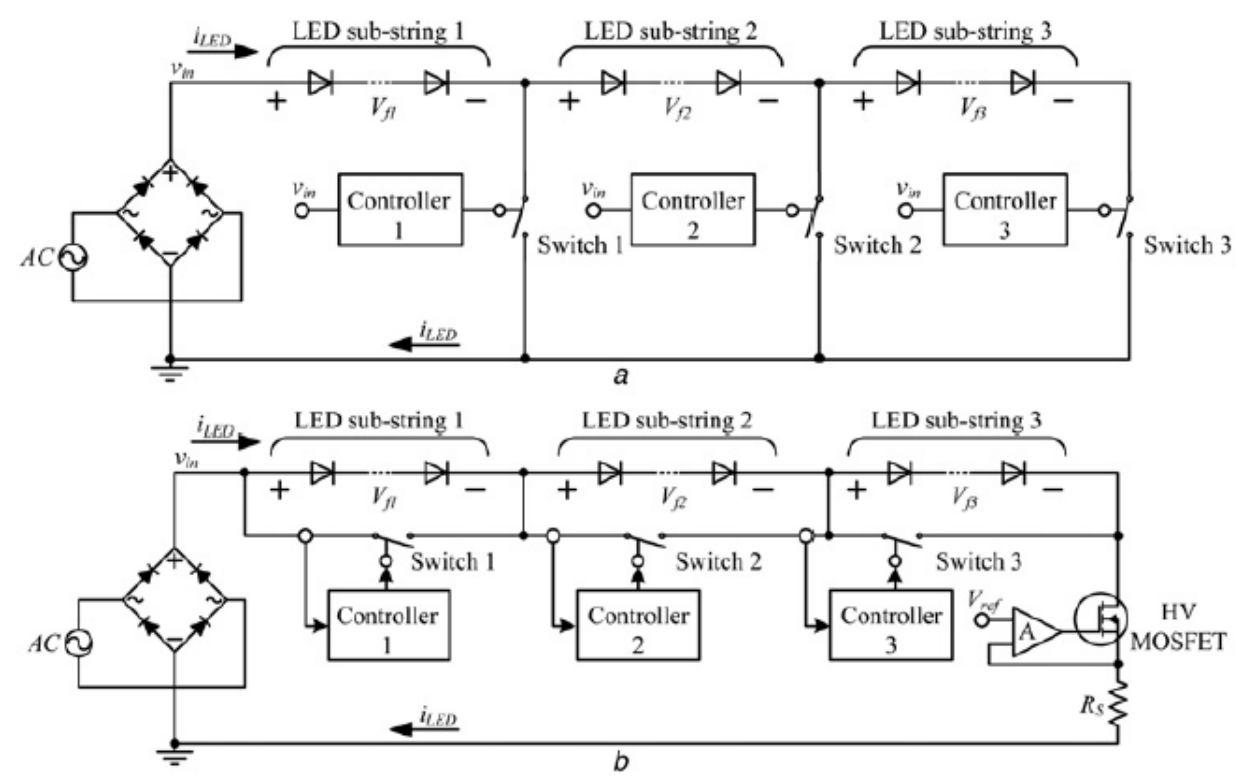

Figure 2-1: A series switching system (top) and parallel switching system (bottom) [11].

In most common AC LED systems, there are two ways to place the switches, and two different schemes to switch them. Systems either have the switches in parallel with the LED strings, or in series with the LED strings. In a parallel switching configuration, the switch is used to direct current away from the LED string. This can be seen in Figure 2-1 (bottom). In a series configuration, the switch connects each string to ground in order (Figure 2-1, top) [11]. 

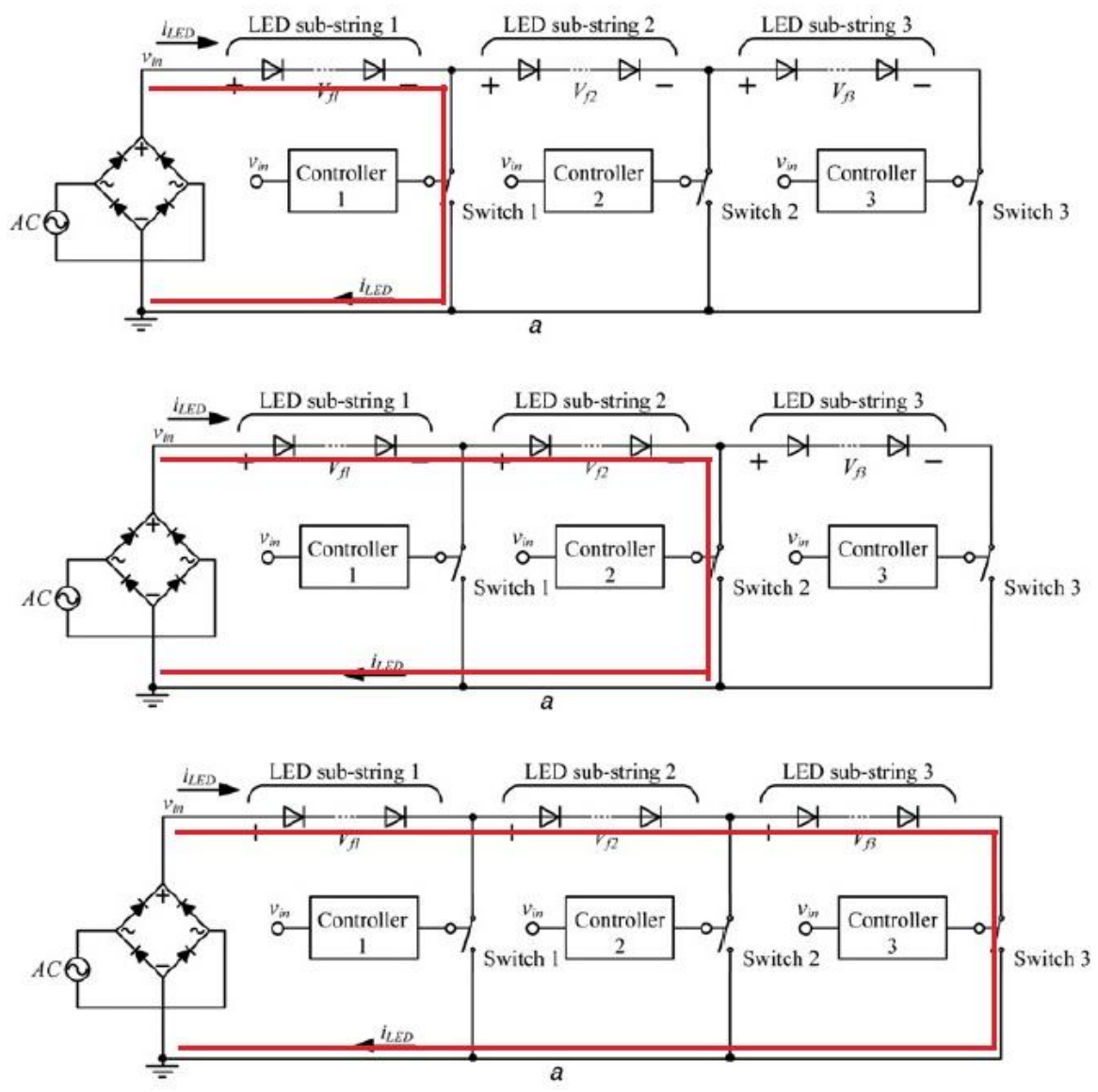

Figure 2-2: Augmented diagram showing three switch states in a series configuration [11].

Within these two methods of configuring the switches, there are two main ways to switch the strings on and off. One, usually used with the series switch topology, is to turn on the strings in order as input voltage increases. This can be seen in Figure 2-2. As the input increases, more and more LEDs are turned on by turning on a single switch after the desired number of strings.

This can be done in a parallel configuration as well, with simply the opposite logic (when switch is off, LEDs are on). One commercial example of the step-up switching method is the Fairchild FL77944, which is close to an all-in-one IC that has internal MOSFETs in series with off-chip LEDs. The shunt regulator is integrated, and for lower power systems the IC does everything needed in a small package [12].

The other switching scheme used is where the switches are altered in a binary counting method. This can only be used with a parallel topology since it necessitates the ability to turn on 
any one string or combination at any time. In a series topology, only a string and all below it can be turned on. In this binary switching, the switch states are similar to a binary truth table with $2^{\text {n }}$ (where $\mathrm{n}$ is the number of switches) states possible. If the number of LEDs in each string doubles ( 1 in the first string, 2 in the next, 4 in the third, etc.), then the number of LEDs on increases by one for each increasing switching state. This improves power factor and THD, since the voltage across the LEDs can more closely follow the input rectified sinusoid.

One commercial example of a parallel, binary switching configuration is using the Texas Instruments TPS92411 switches with the TPS92410 linear regulator. This semiconductor switch has a built-in MOSFET, but each switch is in its own package. This allows for different size systems, built from a single building block. Most examples are systems in the under-50W range, but its scalability allows it to potentially be used for higher power [13].

The article "Dimmable AC LED Driver Based on Series Drive" by K.I. Hwu and Jenn-Jong Shieh is an example of a design that utilizes a parallel configuration with step-up switching [14]. Rather than achieving different LED stack combinations with binary switching, this is done by weighting the number of LEDs in each stack. An example with ten stacks is in Table 2-3.

Table 2-3: LED stack count for each string according to Hwu's method [14].

COUNT FOR EACH LED STRING

\begin{tabular}{lc}
\hline \hline LED string & Count \\
\hline$L S_{1}$ & 2 \\
$L S_{2}$ & 7 \\
$L S_{3}$ & 6 \\
$L S_{4}$ & 6 \\
$L S_{5}$ & 5 \\
$L S_{6}$ & 5 \\
$L S_{7}$ & 4 \\
$L S_{8}$ & 3 \\
$L S_{9}$ & 3 \\
$L S_{10}$ & 1 \\
\hline \hline
\end{tabular}


Hwu divides the input cycle into even time intervals, adding a new stack in each interval for the first quarter of a cycle. Then the order is reversed as the input decreases again. This LED stack configuration allows the total LED stack voltage to closely follow the input voltage, while considering the drop across the rectifier and linear regulator [14].

The other inherent problem with AC LED systems that Hwu's design solves is driving the essentially "high side" main switches. Since the stacks of a parallel AC LED system are floating above ground, the source of each switch (if using MOSFETs) is not grounded so a driver must be used to reliably turn them on and off. To bridge the gap between standard logic levels and the main switches, this article uses PNP BJT transistors for the main switches, with NMOS MOSFET transistors to drive them from standard logic levels (see Figure 2-3) [14]. This technique is unique among documented examples of AC LED driving and could be a significant cost savings when compared with traditional high-side gate drive IC's. This design overall is strong, but the number of LED stacks could be reduced with a binary switching scheme instead of a step-up.

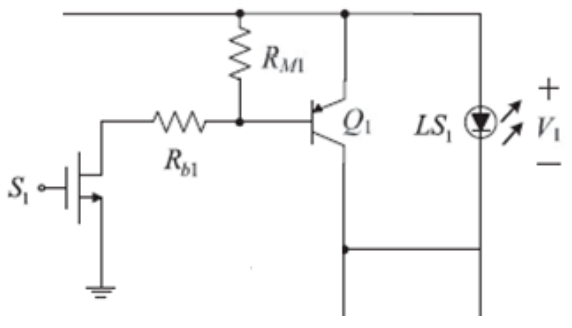

Figure 2-3: Hwu switch control method avoiding gate driving IC [14].

A paper by Changbyung Park and Chun-Taek Rim proposes a design with discrete digital logic and a binary counter to control a set of seven binary-weighted LED stacks (one LED in stack one, two in stack two, four in stack three, etc.) to accomplish AC direct drive. This paper is unique in its use of discrete digital logic and binary counter (implemented using a microcontroller in the prototype experiment) [15]. Figure 2-4 shows the block diagram of this system, where the reference generation and comparator blocks drive the binary counter. The type of MOSFET gate driver used for the main switches is not specified. This design compacts the number of switches with the binary weighted LED stacks. There are 127 LEDs in seven stacks, versus 42 LEDs in ten stacks in the previous solution. Less stacks reduces cost, especially when using gate driving IC's. 
Also, binary counting with a smallest stack of one LED means the input voltage can be followed with a resolution of the forward voltage of a single LED. This reduces loss on the linear regulator, and it is a good strategy to follow.

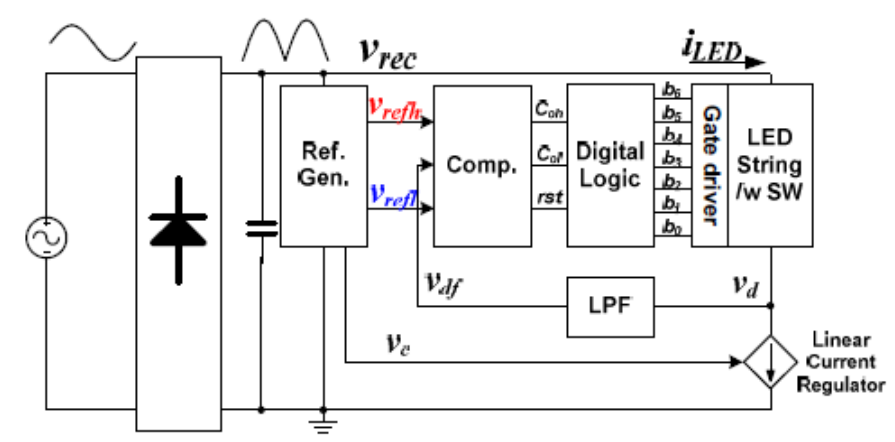

Figure 2-4: Block-level diagram of proposed system with binary counter [15].

Another common issue with the AC direct drive is flicker. Since the brightness of the system is always changing and there is dead time with no LEDs on, there is inherent flicker with this approach, typically at double the line frequency $(120 \mathrm{~Hz}$ in the US). Normally, anything blinking much faster than $20-30 \mathrm{~Hz}$ is invisible to the human eye, but during saccades, rapid movements of the eye, people can see things changing at much higher frequencies. This is like when you are on a speeding train but by darting your eyes quickly you can read a street sign going by outside. When working under flickering lights for long periods, like in an office, the flicker is hardly consciously noticed but can cause headaches in some people. Most studies done so far focus on CFL lights and not LEDs, but it is likely the same principles apply [16].

Percent flicker is defined by the equation: percent flicker $=\frac{\max -\min }{\max +\min } * 100$, where $\max$ and min are the brightness of the light source. This can be measured in different ways, one is with a photodiode and a simple op amp circuit to convert current into voltage, which is then observed on an oscilloscope [17]. Flicker Index is also a commonly measured metric to compare light flicker. This is determined by two areas under the curve of brightness of the light. The equation for flicker index is as follows, according to Figure 2-5: flicker index $=\frac{\text { area } 1}{\text { area } 1+\text { area } 2}$. The result ranges from zero to one, a lower value meaning less flicker. Flicker is a difficult metric to quantify, since its effects depend entirely on how humans perceive light sources. Neither flicker index or flicker percentage correspond to human perception, but they are simple to test and allow 
some comparison between topologies [18]. The International Electrotechnical Commission (IEC) has proposed a standard, IEC $61000-4-15$, that outlines a way to properly measure and quantify flicker in lighting, taking into account human perception to create a more meaningful metric [19]. This is beyond the scope of this investigation focusing on efficiency but would be an important standard for a project focused on flicker.

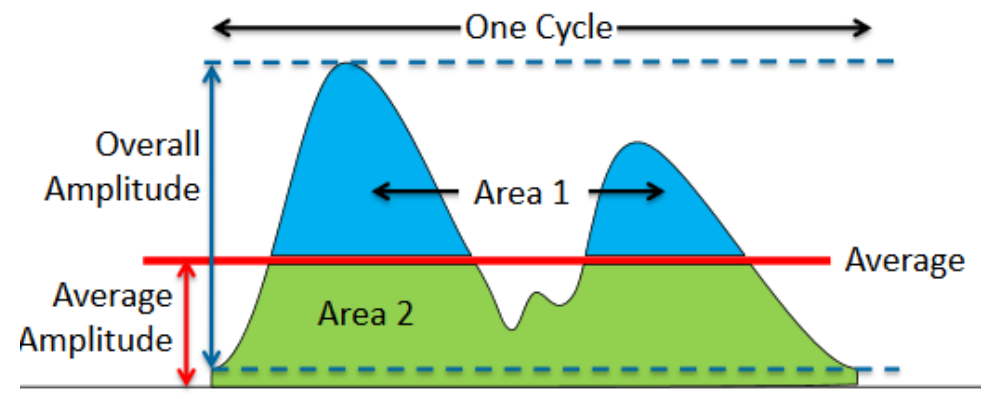

Figure 2-5: Representation of two ways to quantify flicker.

A paper titled "A Direct AC Driver with Reduced Flicker for Multiple String LEDs" by Junsik Kim and Shihong Park discusses two versions of a "valley fill" circuit. In this paper, reducing flicker in an AC LED system is done by ensuring there is always enough input voltage to keep the lower stacks on. Figure 2-6 shows a traditional valley fill circuit used in an AC led system. Each capacitor is charged to $1 / 2 V_{\text {in }}$, so that when the input falls below $1 / 2 V_{\text {in }}$, the charge is sourced from the capacitors, keeping LED stack one and two on all the time. This removes the dead time with no LEDs on and reduces the amplitude of the brightness change. The new version proposed in the paper, as shown in Figure 2-7, uses a comparator and two MOSFETs to charge a single capacitor to $V_{\text {in. }}$. This not only keeps the bottom stacks on during the entire cycle but also allows a second pulse of light from the other two stacks during a cycle, effectively doubling the flicker frequency so that it is harder to see. The paper cites an inevitable tradeoff between power factor and flicker, since the input current is becoming narrower (less sinusoidal), but if flicker were a key design restraint this represents one way to solve that problem [20]. 


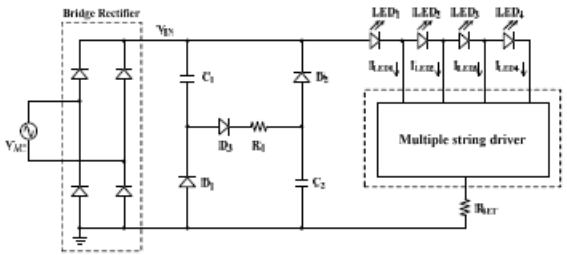

Fig. 4. Conventional scheme for flicker-less (valley fill).

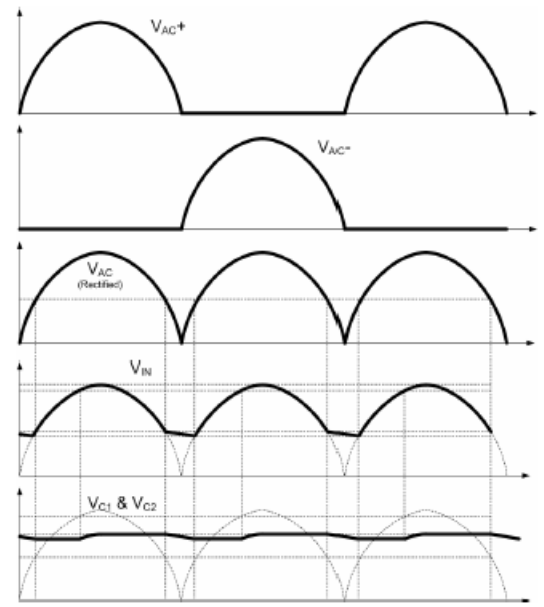

Figure 2-6: Traditional valley fill circuit with capacitors charged to 1/2Vin [20].

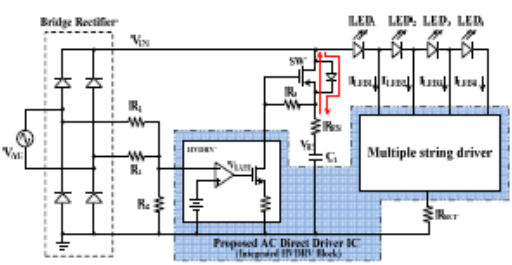

Fig. 7. Proposed scheme for flicker-less.

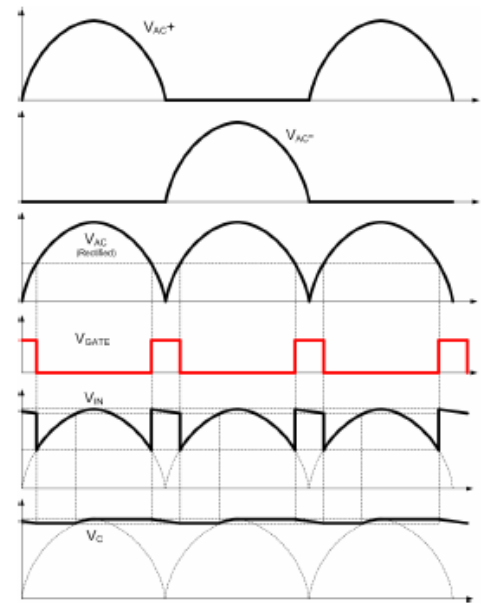

Figure 2-7: Proposed modified valley fill with capacitor charged to Vin [20].

The goal of this project is to design, simulate, build, and characterize an AC direct drive LED system, with topology based on the research discussed above. It will be a modification of the parallel topology with binary switching, using analog control circuitry. This should eliminate large capacitors and microcontrollers from the system, as well as costly gate driving ICs if possible. This should further create a simple, cost effective option for AC LED lighting. 


\section{Chapter 3 : DESIGN REQUIREMENTS}

The level 0 diagram of the AC LED system as illustrated in Figure $3-1$ shows the input is scaled down $60 \mathrm{~Hz}$ AC power, and the output is light from the LED array. The system will be designed to have the highest efficiency.

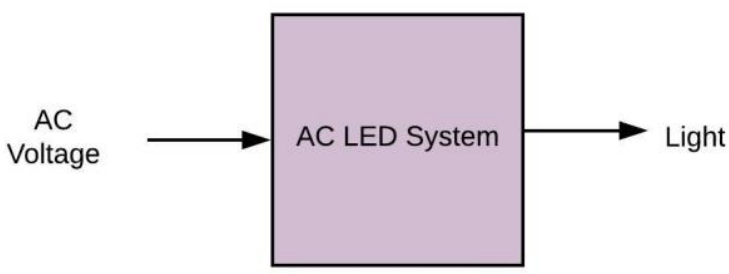

Figure 3-1: Level 0 block diagram of system.

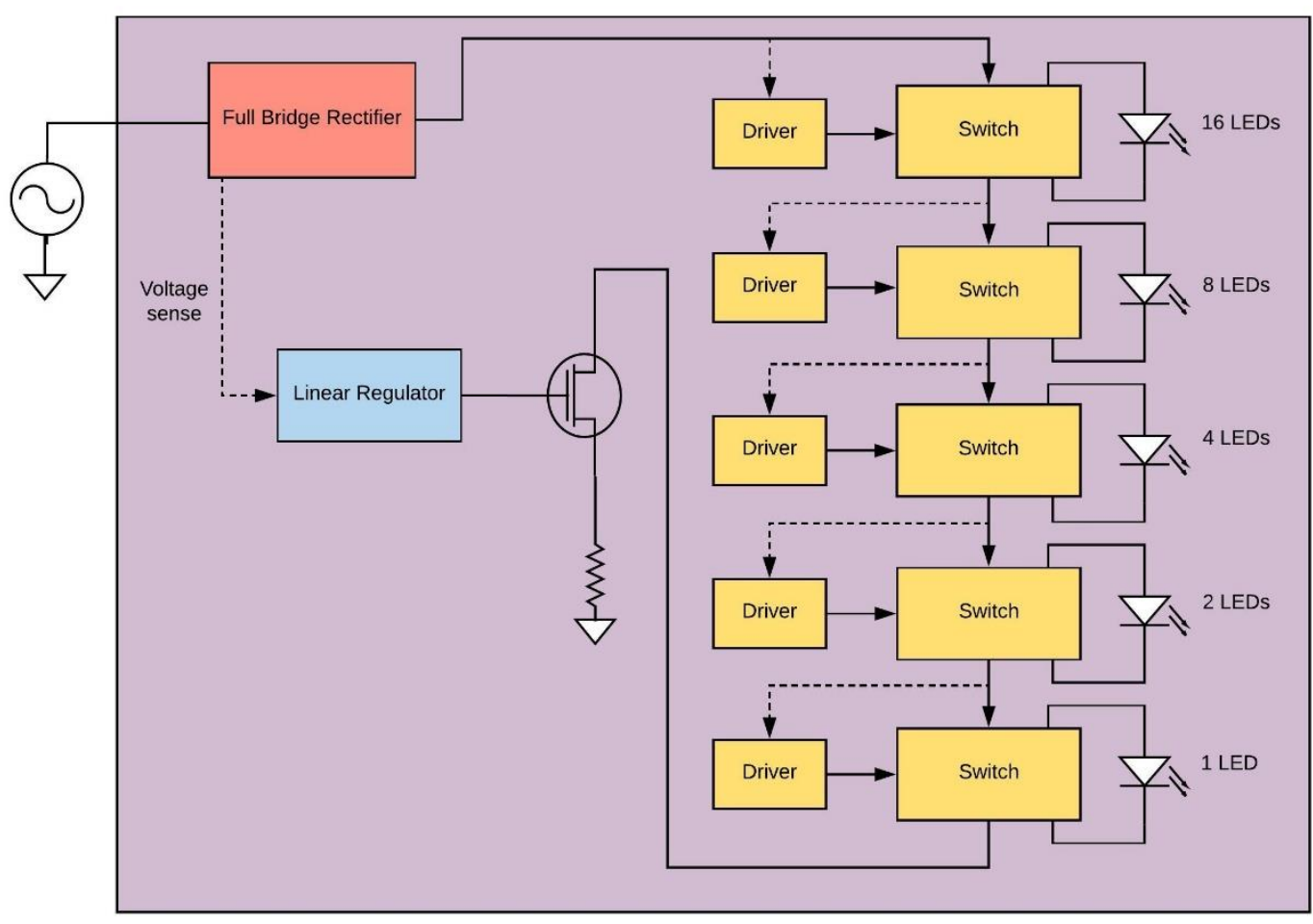

Figure 3-2: Level 1 system block diagram. 
At a finer Level 1 Block Diagram as shown in Figure 3-2, the system can be broken into three main blocks: rectifier, switch/LED stacks, and linear regulator. The full bridge rectifier converts the line voltage so only positive swings go into the system. The switch/LED stacks consist of a solid-state switch, switch driver, and LED string. The analog logic in the switch driver is responsible for determining when the LEDs need to be on as well as properly driving the switch itself. This is done without an external microcontroller, which some example papers use. The switch opens or closes to steer current into or away from the LED stack. The Linear regulator monitors the rectified input voltage and modulates the gate voltage of the regulating MOSFET so that the input current shape follows the input voltage shape and phase for improved power factor. The advantage of an off-board MOSFET is that it can be sized as needed for the rating of the system.

\subsection{Technical Design Requirements:}

The main goal of this project is to build a scaled-down version of a functional AC LED system using common components and without a microcontroller. The design will combine elements of several academic papers, as well as some unique components. The main goal is to verify if the efficiency gains in the previous simulation project can be seen in the physical system. Efficiency, current THD, power factor, brightness, and flicker will be measured on the final system. Table 3-1 summarizes the technical requirements aimed for the AC LED system in this study. 
Table 3-1: Technical requirements of AC LED system.

\begin{tabular}{|c|c|c|}
\hline Specification & Value & Justification \\
\hline Input Source & $\begin{array}{l}100 V_{\text {peak }} \\
60 \mathrm{~Hz}\end{array}$ & This system will use scaled-down AC input power. \\
\hline Efficiency & $\begin{array}{c}\text { Greater than } \\
85 \%\end{array}$ & $\begin{array}{l}\text { The TI (Texas Instruments) reference design starts near } 85 \% \\
\text { efficiency, so high-loss areas will be identified and improved upon. } \\
\text { This is the most important goal of the project. }\end{array}$ \\
\hline Power Factor & 0.8 & $\begin{array}{l}\text { High power factor ensures the system is not requiring excessive } \\
\text { reactive power. The linear regulator helps on this aspect. }\end{array}$ \\
\hline THD & TBD & $\begin{array}{l}\text { Low THD is necessary to keep power quality high and not inject } \\
\text { excessive harmonics into the grid; however, the goal of this project is } \\
\text { to increase efficiency and analyze tradeoffs that result. }\end{array}$ \\
\hline Flicker & TBD & $\begin{array}{l}\text { Flicker is largely dependent on use. It is unacceptable in an office, } \\
\text { but okay in a parking lot. The goal is to measure the flicker and see } \\
\text { what trade off results from a goal of higher efficiency. }\end{array}$ \\
\hline Size & $N / A$ & $\begin{array}{l}\text { Size is of no concern for this design, other than eliminating large } \\
\text { input capacitors and inductors from a DC-DC system. }\end{array}$ \\
\hline
\end{tabular}




\section{Chapter 4 : SYSTEM DESIGN AND SIMULATION}

The design tested will demonstrate a five-stack, binary switching system. The overall design is based on previous investigation of the subject, with the goal of increasing efficiency of an AC direct drive system [21]. To achieve this, a system will be constructed with common components (comparators, MOSFETs, BJTs, diodes, passives) so that the design is flexible, inexpensive, and potentially adaptable to an IC. For this reason, the switch driving technique from Hwu's paper is implemented to eliminate costly high-side MOSFET driving ICs [14]. The linear regulator in the system is made from discrete components, following a $\mathrm{TI}$ application note [22]. The switch control is a new method based on voltage sense resistors and comparators. This is more simple, cost-effective, and adaptable than a microcontroller-based control system.

\subsection{Previous Simulation Investigation:}

The goal of this project was to develop a flexible simulation of an AC LED system to find areas of significant power loss and attempt to improve them. This allowed this thesis investigation to begin with major loss areas in mind, reducing development time and increasing performance. Systems tested included a three-stack binary switching system, a four-stack step-up switching system, a four-stack binary switching system, and a five-stack binary switching system. Through each simulation, the common theme was that the loss of the linear regulator was the dominant loss of the system. It was found that by adding smaller stacks of LEDs, the total voltage dropped across all stacks could be altered with finer resolution, and the loss of the MOSFET could be reduced significantly by reducing the voltage dropped across it. With three stacks using binary switching, MOSFET loss was $22.4 \mathrm{~W}$, or $29 \%$ of input power. With five switches, the MOSFET loss was reduced to $333 \mathrm{~mW}$, or less than $1 \%$ of input power.

To begin, a flexible simulation was created that allowed the LED stack voltage, MOSFET sinking current, component choices, and switch signals to be adjusted for different methods. This is accomplished by using LTSPICE. Instead of a real switch, voltage-controlled switches with piecewise linear voltage sources (as controls) were used to allow for custom switching schemes (see Figure 4-1). The TPS92411 datasheet states the built-in MOSFET has an $R_{D S o n}$ of $2 \Omega$, so the on-resistance of the switch in the simulation is set at $2 \Omega$ as well, for a baseline to work from [22]. 


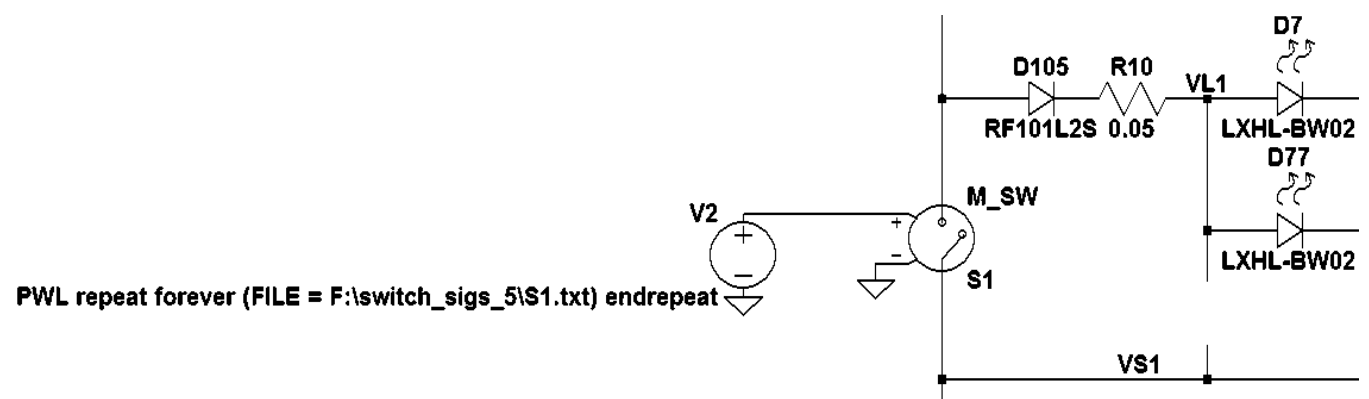

Figure 4-1: Example of a single voltage-controlled switch reading from a control file periodically.

For the linear regulator in the system, a design made from discrete components is chosen for maximum flexibility in variations of the baseline system [22]. It also allows for more analysis of the functionality than a chip that abstracts some of the function away. The goal of this regulator is to limit current through the branches of LEDs for a desired output power, as well as to improve power factor by ensuring the shape of the input current better matches the shape of the input voltage. The regulator uses a resistive divider (R1 and R6 in Figure 4-2) to sample the input voltage, using large values for minimum current and loss. This voltage drives the gate of the current regulating MOSFET, with a feedback obtained from a sense/current-limiting resistor between the source of the MOSFET and ground. This resistor is used to set the current through the MOSFET, and by extension the output power since this current is sent though the LED stacks. This regulator was used for all designs in this particular investigation, with changes to the source resistor to set the output power.

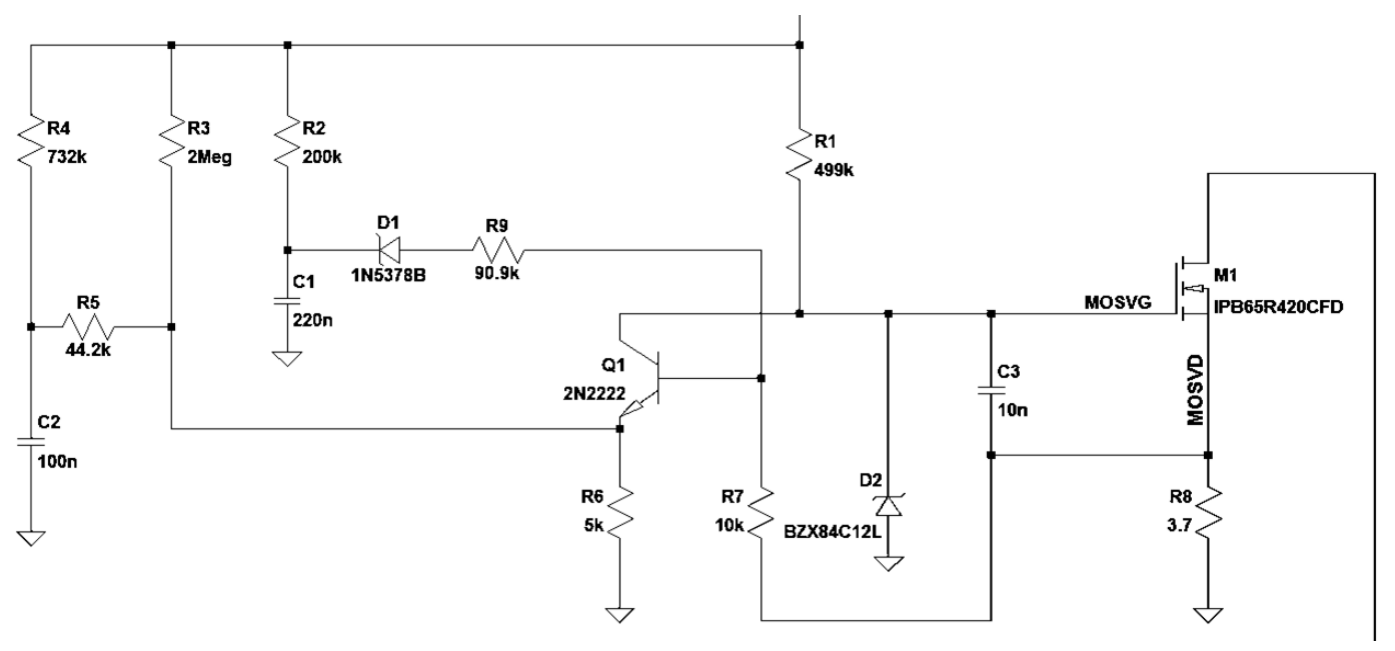

Figure 4-2: Discrete linear regulator used for all testing. 
In this simulation, a model for Luxeon LXHL-BW02 is utilized to approximate the LEDs in the system.

\subsection{Simulation Data Collection Methods:}

The same measurements are taken for each topology/switching method to enable easy comparison between them. Some are simple waveform captures such as LED stack voltages (voltage across the switches/LED stacks), stack currents (current through each LED stack), piecewise linear voltage source signals, and MOSFET drain current and drain-to-source voltage.

Some other characteristics require calculations. Since efficiency is the most important focus of this project, the input and output power must be calculated, as well as power lost by the input rectifier, switches, MOSFET, and source resistor. All are calculated and then the average of the instantaneous power over an integer number of periods is recorded. These are measured in simulation as follows to yield input power (in Watts):

$$
P_{\text {in }}=A V G\left(\left(V_{a}-V_{b}\right) * I_{\text {source }}\right)
$$

where $V_{a}$ and $V_{b}$ denote the voltage potential on either end of the voltage source in the input rectifier, and $I_{\text {source }}$ is the current drawn from this source. The output power equation in Watts is given as:

$$
P_{\text {out }}=A V G\left(\left(V_{l 1}-V_{s 1}\right) * I_{R 10}+\left(V_{l 2}-V_{s 2}\right) * I_{R 11}+\cdots\right)
$$

where $V_{\ln }$ is the voltage on the top of LED stack $\mathrm{n}$ (after the blocking diode and sense resistor), $V_{s n}$ is the voltage on the bottom of LED stack $n$, and $I_{R 1 n}$ is the current through sense resistor $R_{1 n}$ of stack $\mathrm{n}$ in series with the LEDs. This summation is completed for each stack in the given design, either three, four, or five stacks. The power absorbed by the rectifier is (in Watts):

$$
P_{\text {rect }}=A V G\left(V_{D 1} * I_{D 1}+V_{D 2} * I_{D 2}+V_{D 3} * I_{D 3}+V_{D 4} * I_{D 4}\right)
$$

where $V_{D n}$ is the voltage across rectifying diode $n$, and $I_{n}$ is the current through rectifying diode $n$. MOSFET power loss (in Watts) can be calculated by:

$$
\begin{gathered}
P_{M O S F E T}=A V G\left(V_{D S} * I_{D}+V_{G S} * I_{G}\right) \\
P_{R S}=A V G\left(V_{S} * I_{D}\right)
\end{gathered}
$$


where $V_{D S}$ is the drain-to-source voltage of the MOSFET, $V_{G S}$ is the gate-to-source voltage, $I_{D}$ is the drain current, $\mathrm{I}_{\mathrm{G}}$ is the gate current, and $\mathrm{V}_{\mathrm{S}}$ is the source voltage of the MOSFET.

Also captured is the input voltage and current, which are used to calculate power factor as follows, where linRms is measured in simulation.

$$
P F=\frac{P}{S}=\frac{P_{\text {in }}}{V_{\text {inRMS }} I_{\text {inRMS }}}
$$

Finally, efficiency is calculated with the ratio of average output power to average input power.

$$
\eta=\frac{P_{\text {out }}}{P_{\text {in }}}
$$

\subsection{Dominant Losses in the System:}

The losses in this system are dominated by the rectifier diodes, the switches, and the linear regulator. The regulator (MOSFET and $\mathrm{R}_{\text {source}}$ ) is the dominant loss in most cases, as would be expected from a linear regulator.

In this system, any voltage not dropped on the LEDs is dropped across the MOSFET. Since the current is regulated and set by the desired output power, the $V^{*}$ l losses on the MOSFET are solely a function of the voltage across it. By Kirchoff's Voltage Law, during a half cycle of the input:

$$
\begin{gathered}
V_{\text {in }}=2 * V_{\text {rect. diode }}+V_{L E D S}+V_{M O S F E T}+V_{R S} \\
V_{\text {MOSFET }}=V_{\text {in }}-\left(2 * V_{\text {rect. diode }}+V_{L E D S}+V_{R S}\right)
\end{gathered}
$$

The voltage drops from the rectifier diodes and source resistor are both a function of the current in the system, which is restrained by the output power requirement. Therefore, these are relatively constant. Recall:

$$
P_{\text {MOSFET }}\left(V_{\text {MOSFET }}\right) \approx A V G\left(V_{M O S F E T} * I_{D}\right)
$$

Since the drain current is restrained by output power, power loss of the MOSFET is determined entirely by the voltage across it. This is, in turn, entirely determined by the number of switches, LED stack voltages, and switching signals. Since MOSFET loss is dominant, the only significant way to increase efficiency is to alter these aspects of a system. This is true for all configurations 
and will be observed throughout these tests. This is the motivation behind primarily testing different switching styles and not component types.

\subsection{Previous Investigation: Five-Stack, Binary Custom Switching}

This configuration proved to be the most efficient of the ones tested, so it was used to create the physical system. A fifth stack of LEDs was added with the goal of further reducing the voltage dropped across the MOSFET. See Appendix A for full schematic. Since an additional stack would have a very low voltage, it can fill in more places where there is enough headroom to turn the stack on. By starting with the previous configuration's switch scheme, baseline efficiency is acceptable, and any changes should improve from there. The specifications of this configuration are shown in Table 4-1 and Figure 4-3.

Table 4-1: Summary of configuration 5 from the previous investigation.

\begin{tabular}{|c|c|}
\hline Number of LED stacks & 5 \\
\hline Switching style & Custom/Binary \\
\hline Stack one size & $83 \mathrm{~V}, 26$ LEDs \\
\hline Stack two size & $42 \mathrm{~V}, 13 \mathrm{LEDs}$ \\
\hline Stack three size & $23 \mathrm{~V}, 7$ LEDs \\
\hline Stack four size & $10 \mathrm{~V}, 3$ LEDs \\
\hline Stack five size & $7 \mathrm{~V}, 2$ LEDs \\
\hline Rsource & $3.7 \Omega$ \\
\hline
\end{tabular}

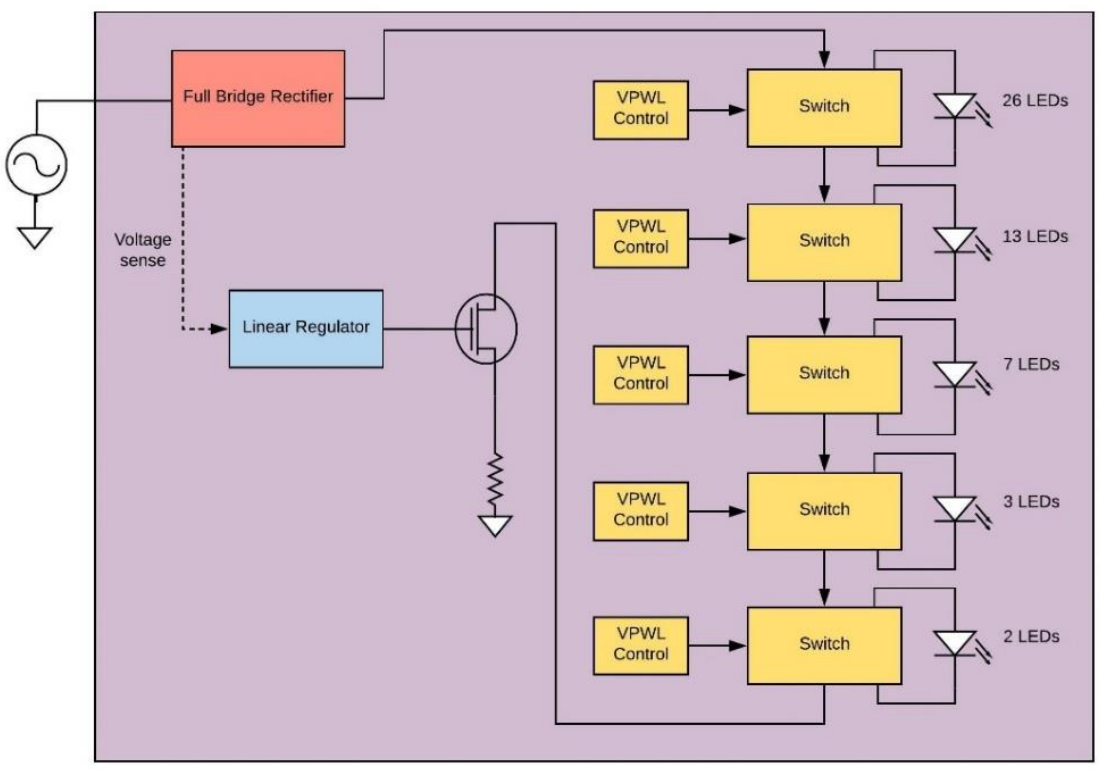

Figure 4-3: Block diagram description of configuration 5 of the previous investigation. 
To begin the design of adding a fifth switch, the switch signal of the fourth stack was modified first. By assessing the MOSFET voltage waveform, time periods where there was enough headroom to activate the fourth switch were identified and added to the control file for switch four. Figure 4-4 demonstrates this process, with areas added in red. Once these additions were verified, the process was repeated with headroom of $7 \mathrm{~V}$, for a fifth stack with two LEDs.

This stack was added in series with the rest, with the same type of voltage control. The switching signals are shown in Figure 4-5.

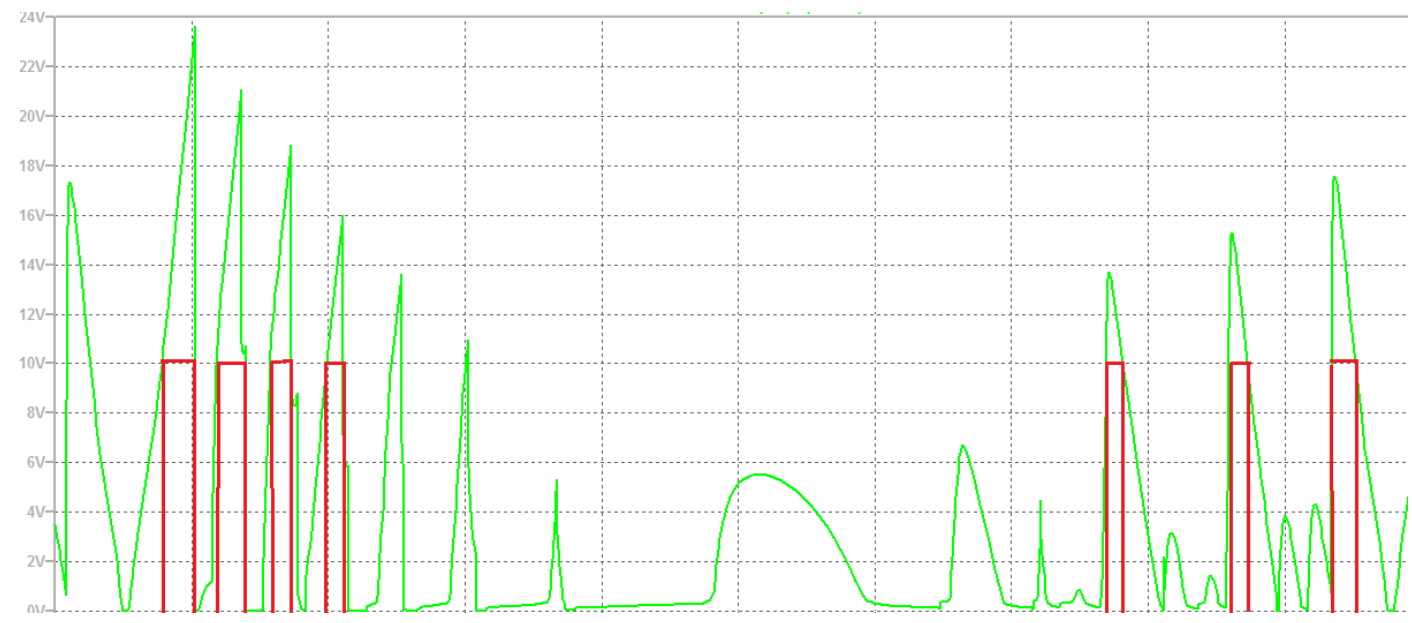

Figure 4-4: Example demonstrating where extra switch signals were added to improve beyond configuration 3.

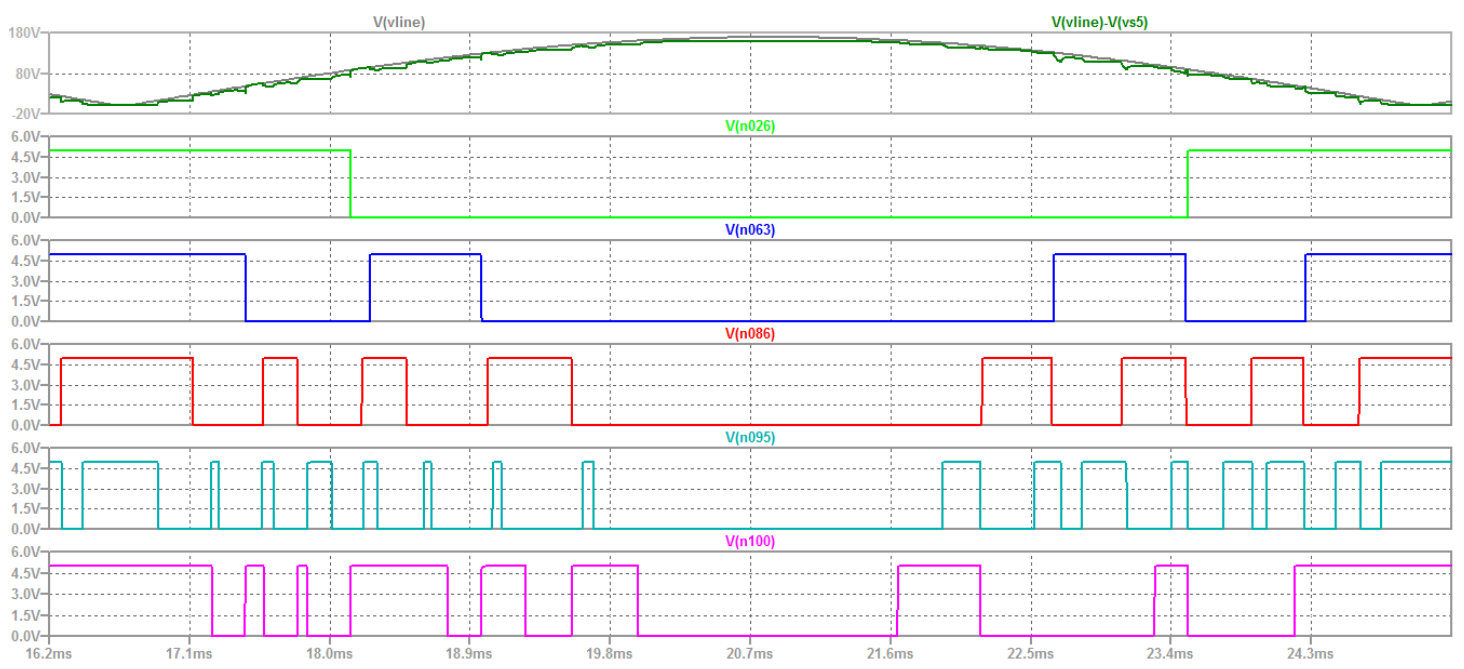

Figure 4-5: From top to bottom: Rectified input voltage and total stack voltage, switch signal one, switch signal two, switch signal three, switch signal four, switch signal five. 
Figure 4-6 and Figure 4-7 show the new LED stack voltages and currents, respectively. The addition of the fifth stack required removing two LEDs from the largest stack and one LED from the second stack. This is reflected in the voltage of these stacks. These figures demonstrate the current set by the regulator is steered as designed.

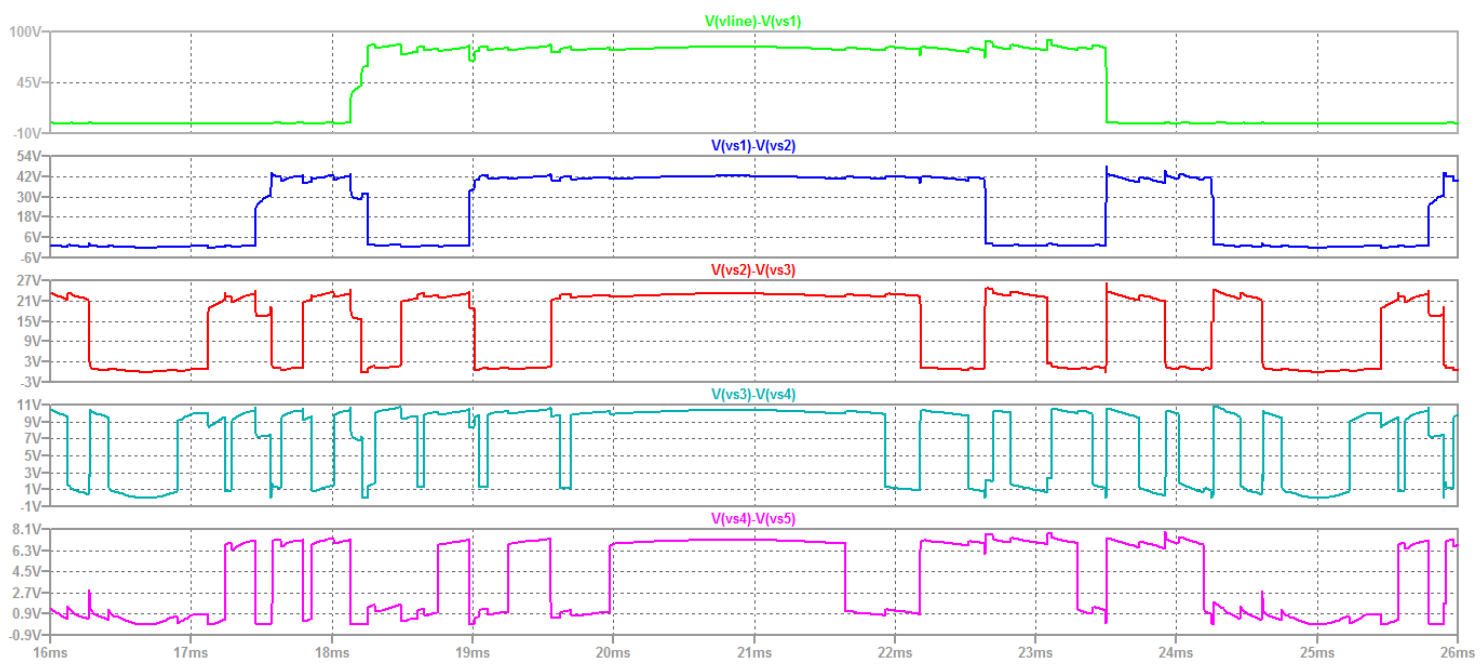

Figure 4-6: From top to bottom: voltage across stack one, two, three, four, five.

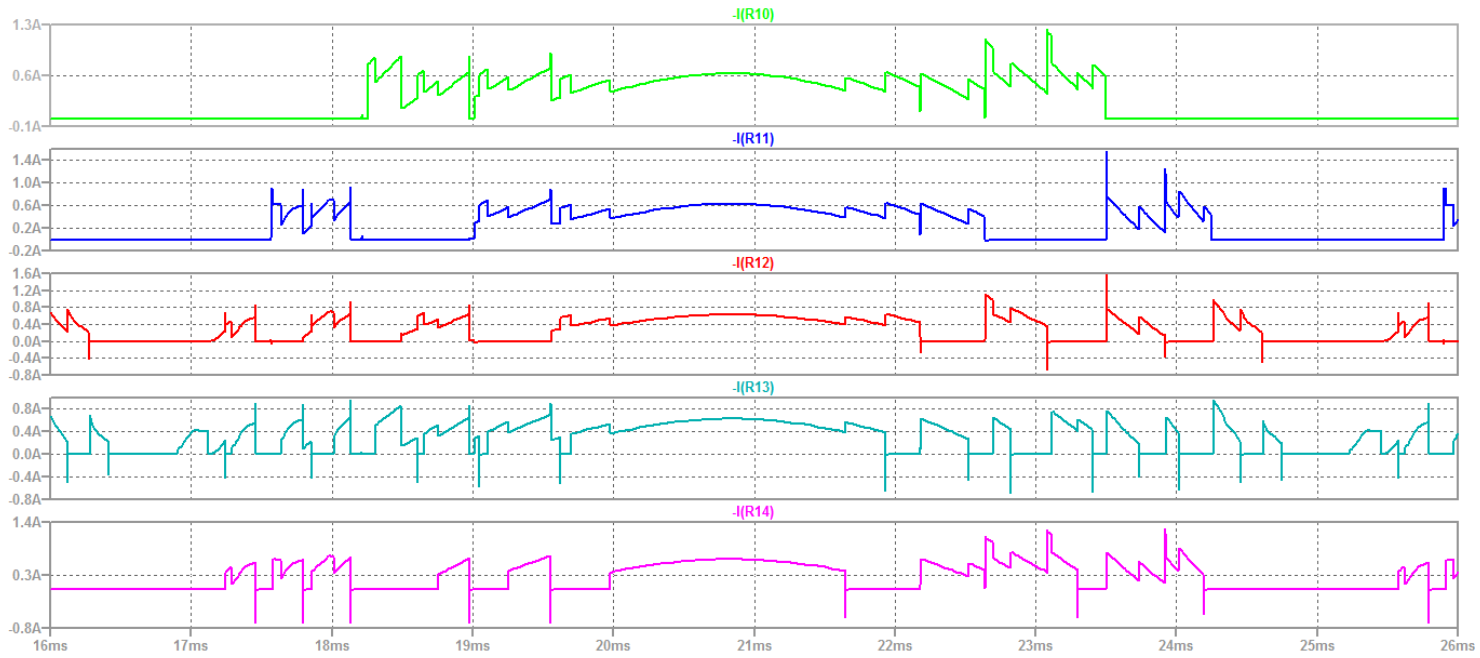

Figure 4-7: From top to bottom: current through stack one, two, three, four, five.

With the addition of the fifth switch, voltage across the MOSFET can be reduced significantly, as seen in Figure 4-8. This is a significant improvement over other configurations tested. The current remains in phase with the voltage, but additional switching and less voltage across the linear regulator makes it noisier, degrading THD. Input voltage and current can be seen in Figure 4-9. 


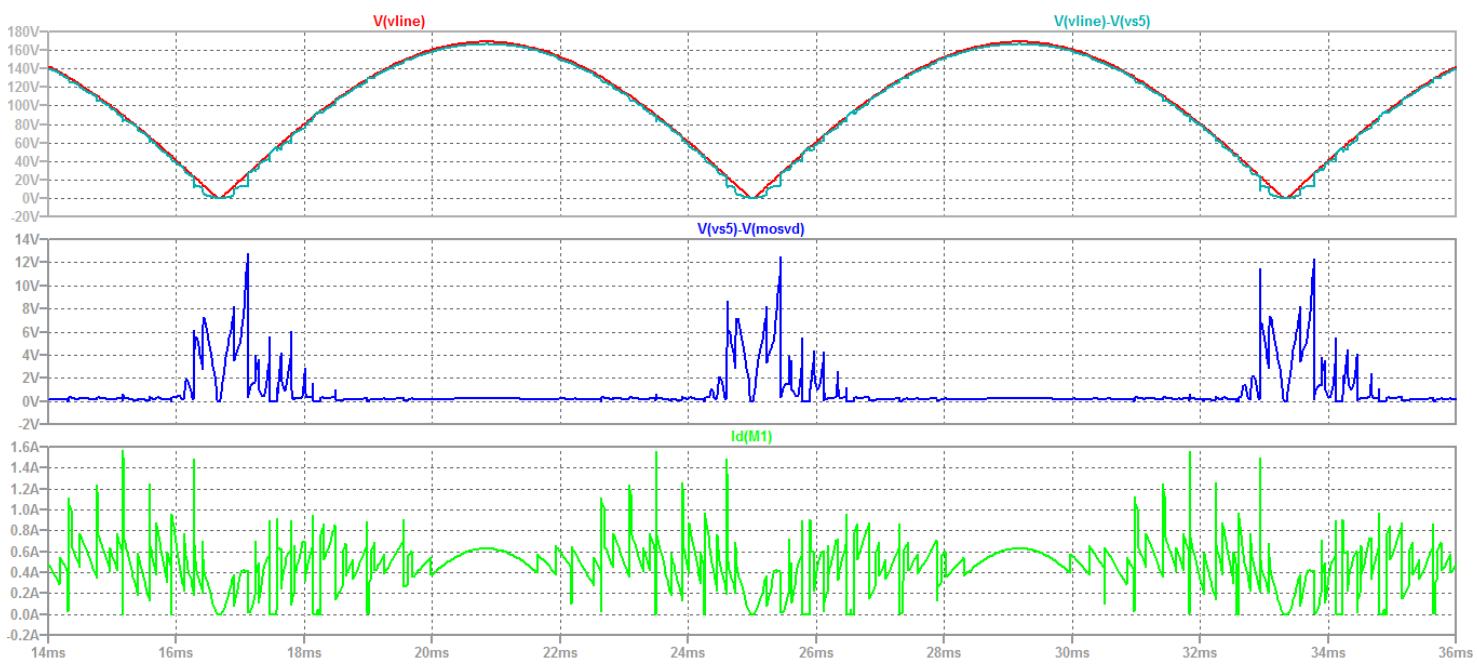

Figure 4-8: From top to bottom: Rectified input voltage and total LED stack voltage, MOSFET drain-to-source voltage, MOSFET drain current.

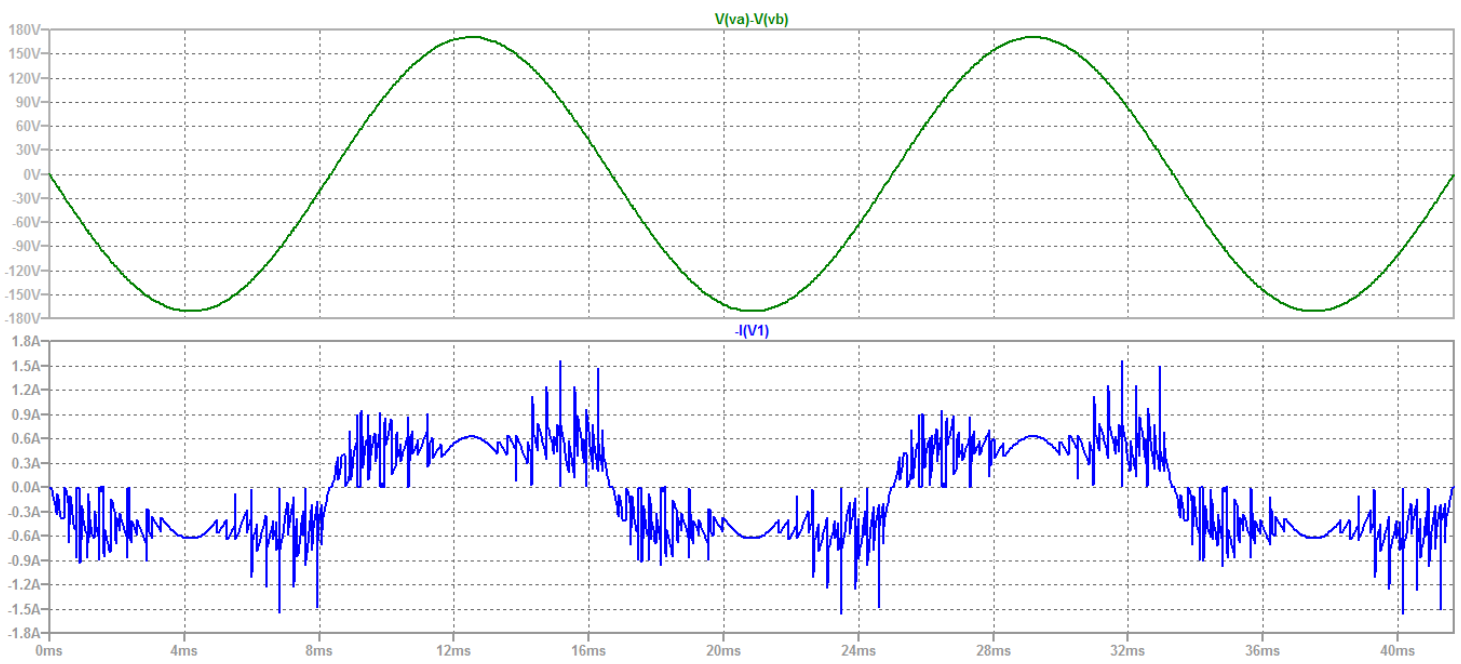

Figure 4-9: Input characteristic (voltage top, current bottom) of configuration 4.

The losses resulted from this configuration are summarized in Table 4-2. Overall efficiency is improved approximately $2 \%$ from the previous version by adding an additional switch. This is mainly due to the reduced MOSFET loss, from $1.6 \mathrm{~W}$ to $333 \mathrm{~mW}$. This is a $79 \%$ reduction in MOSFET loss from configuration 3 . The rectifier and switch losses are relatively constant, as expected. Also, the addition of the extra stack of LEDs means that for the same output power, less current is needed in the system. This reduced the PRs loss to under $1 \mathrm{~W}$. Figure 4-10 shows a visual representation of the use of input power in the system [21]. 
Table 4-2: Summary of power use in configuration 4.

\begin{tabular}{|c|c|}
\hline $\mathbf{P}_{\text {in }}$ & $55.546 \mathrm{~W}$ \\
\hline $\mathbf{P}_{\text {out }}$ & $51.163 \mathrm{~W}$ \\
\hline $\mathbf{P}_{\text {MOS }}$ & $\mathbf{0 . 3 3 3 W}$ \\
\hline $\mathbf{P}_{\text {RS }}$ & $0.966 \mathrm{~W}$ \\
\hline $\mathbf{P}_{\text {RECT }}$ & $0.851 \mathrm{~W}$ \\
\hline $\mathbf{P}_{\text {SW }}$ & $0.893 \mathrm{~W}$ \\
\hline $\boldsymbol{\eta}$ & $92.10 \%$ \\
\hline
\end{tabular}

Power Use in Five-Stack, Custom Switching Configuration

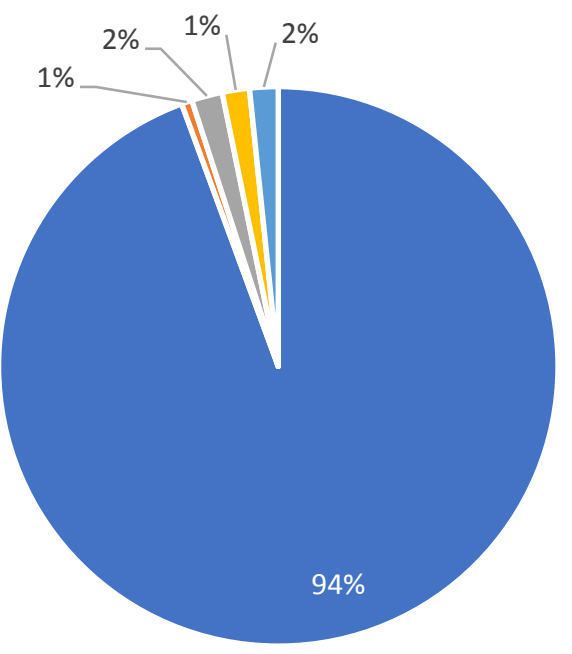

Figure 4-10: Power use as a percentage of input power.

\subsection{Further Configurations: Why not more switches?}

The data for each system, summarized together in Table 4-3, show a trend that having more switches reduces loss in the system. Why not keep adding more? Unfortunately, without radically modifying the size of the LED stacks or concept of switching schemes, five switches is likely the limit for a practical system.

Table 4-3: Summary of power use in all configurations.

\begin{tabular}{|c|c|c|c|c|}
\hline & $\begin{array}{c}\text { Three Stack } \\
\text { Binary }\end{array}$ & $\begin{array}{c}\text { Four Switch } \\
\text { Step-up }\end{array}$ & $\begin{array}{c}\text { Four Switch } \\
\text { Binary }\end{array}$ & $\begin{array}{c}\text { Five Switch } \\
\text { Binary }\end{array}$ \\
\hline $\mathbf{P}_{\text {in }}$ & $78.984 \mathrm{~W}$ & $69.346 \mathrm{~W}$ & $56.523 \mathrm{~W}$ & $55.546 \mathrm{~W}$ \\
\hline $\mathbf{P}_{\text {out }}$ & $51.536 \mathrm{~W}$ & $51.140 \mathrm{~W}$ & $51.115 \mathrm{~W}$ & $51.163 \mathrm{~W}$ \\
\hline $\mathbf{P}_{\text {MOS }}$ & $22.362 \mathrm{~W}$ & $13.551 \mathrm{~W}$ & $1.593 \mathrm{~W}$ & $0.333 \mathrm{~W}$ \\
\hline $\mathbf{P}_{\text {RS }}$ & $1.734 \mathrm{~W}$ & $1.490 \mathrm{~W}$ & $1.249 \mathrm{~W}$ & $0.966 \mathrm{~W}$ \\
\hline $\mathbf{P}_{\text {RECT }}$ & $1.176 \mathrm{~W}$ & $1.018 \mathrm{~W}$ & $0.811 \mathrm{~W}$ & $0.851 \mathrm{~W}$ \\
\hline $\mathbf{P}_{\text {SW }}$ & $1.303 \mathrm{~W}$ & $0.818 \mathrm{~W}$ & $0.871 \mathrm{~W}$ & $0.893 \mathrm{~W}$ \\
\hline $\boldsymbol{n}$ & $65.24 \%$ & $73.75 \%$ & $90.43 \%$ & $92.10 \%$ \\
\hline
\end{tabular}


First, with a fifth stack of two LEDs, only one more stack could be added, with a single LED. Since a white LED has a drop of 3-3.5V or more at this size current, there is no way to turn on LEDs any sooner than when the input reaches $3.5 \mathrm{~V}$. Figure $4-8$ shows that the only significant voltage drop on the MOSFET is during the very beginning and end of the cycle. The sections of the waveform that would allow a $3.5 \mathrm{~V}$ stack to be on are so short, that it would likely be impractical to implement in a physical system.

Finally, with five switches, the MOSFET loss is no longer dominant. To improve efficiency, other aspects of the system need to be altered. The new dominant loss is the currentlimiting resistor, but the loss on that resistor is set by the output power. A $50 \mathrm{~W}$ system creates a restraint on the current through the resistor, and the resistance value sets this current, so there is an ${ }^{2} R$ loss that is unavoidable and unchangeable. The linear regulator in this circuit is a simple and necessary solution to regulate current and drop extra voltage, but the tradeoff is a power loss. The fundamental design of this system requires it, so the loss must simply be minimized. More creative solutions or fundamental changes must be made to the system to improve efficiency further.

\subsection{Designing the Real System:}

With the number of stacks and switching scheme determined by the previous investigation, a scaled-down, physically realizable version of this system must be designed. This section describes the design choices of the major components of the system. The main difficulty in going from the previous simulation to a real system is creating the switching signals and controlling real switches.

\subsection{LED Stack Sizing:}

The input voltage of the system is determined by the smallest possible LED stacks. The minimum number of LEDs in five stacks is determined as follows:

$$
\text { Minimum number of LEDs }=\sum_{n=0}^{4} 2^{n}=1+2+4+8+16=31 \text { LEDs }
$$


White lighting LEDs have a typical voltage drop of 2.7 to $3.3 \mathrm{~V}$, so the headroom needed to have $31 \mathrm{LEDs}$ on is between 84 and $102 \mathrm{~V}$. To begin, an input voltage of $100 \mathrm{~V}_{\text {peak }}\left(71.7 \mathrm{~V}_{\mathrm{RMS}}\right)$ is chosen. This is enough to have the LEDs used in simulation all on, with some headroom.

\subsection{Switch and Switch Driver Choice:}

With the overall goal of using common components in mind, the switches and switch drivers should be as simple as possible, avoiding the use of dedicated high-side gate driving ICs. To accomplish this, a PNP switch driven by an N-type MOSFET is chosen, similar to the method described in K.I. Hwu's paper, "Dimmable AC LED Driver based on Series Drive" [14]. This is illustrated in Figure 4-11. The MOSFET is grounded at its source, so standard logic levels can be used to drive it. When the gate is driven high, the MOSFET pulls current from the base of the PNP transistor, allowing current flow through the main switch. When the gate is low, the pull-up resistor ensures the PNP transistor is off, allowing current to flow through the LED stack in parallel.

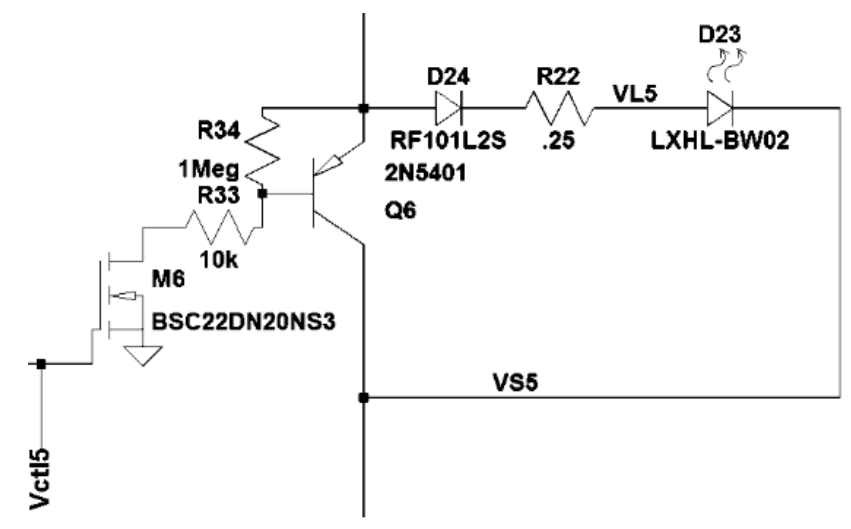

Figure 4-11: Switch and switch driver, N-type MOSFET is used to drive the base of a PNP transistor.

\subsection{Switch Control Hardware and Logic:}

Many papers on the topic of AC LED driving use a microcontroller to determine/control the timing of the switching. A goal of this project is to use analog control hardware built from discrete common components, so a system using voltage sensing and comparators is developed. To accomplish an approximately binary-type logic, a resistive divider is taken between the voltage at the top of a given stack and ground and compared to a reference voltage. Qualitatively, this 
logic asks "Is there enough voltage above this stack to allow it to turn on? If so, turn it on, if not turn it off." This setup is demonstrated generically in Figure 4-12. Note that the logic at the $V_{\text {ctln }}$ pin is inverted (when the signal is high, LEDs are off) due to the nature of the parallel switching setup.

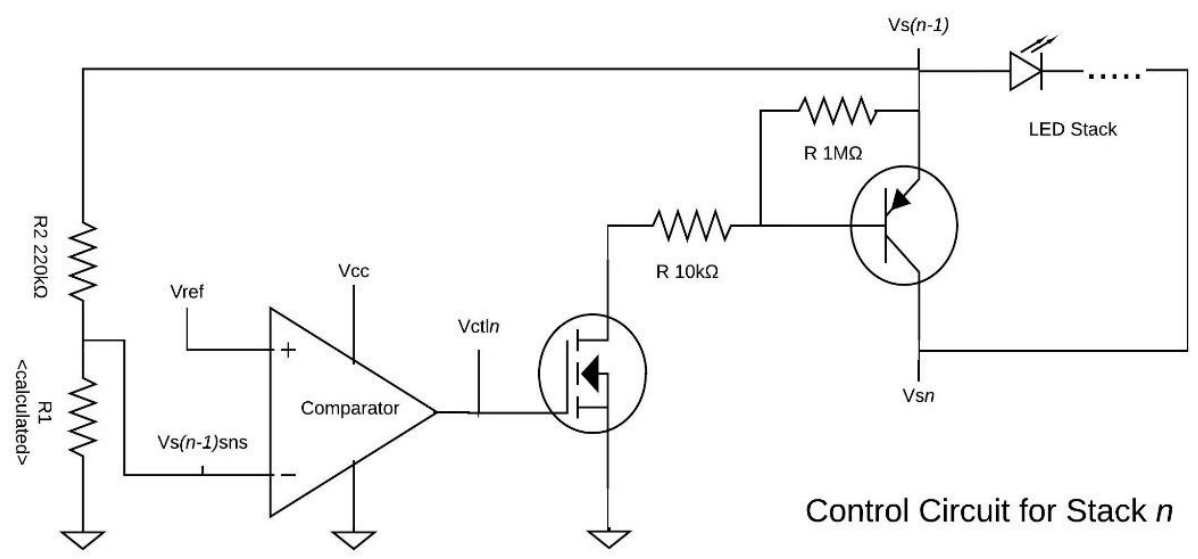

Figure 4-12: A generic version of the control circuitry for this AC LED solution.

In the divider, resistor R2 is set at $220 \mathrm{k} \Omega$ which is a value large enough for a small current draw and loss but a size where $\mathrm{R} 1$ has a reasonable range of values. The calculation below is used to determine the appropriate value of $\mathrm{R} 1$ in the divider.

We want the voltage midway in the divider to be equal to Vref when the sensed voltage is equal to the stack voltage, so:

$$
V_{\text {stack } n} \frac{R_{1}}{R_{1}+R_{2}}=V_{\text {ref }}
$$

This can be rearranged as follows:

$$
R_{1}=\frac{V_{\text {ref }}}{V_{\text {stack } n}-V_{\text {ref }}} R_{2}
$$

This resistor value must of course be rounded to the closest standard $1 \%$ resistor value, but this equation can be used to find a starting point for simulation. The result this design is an analog logic solution that will adapt to small input voltage fluctuations (magnitude/phase/frequency) because the switching sequence is determined by voltage magnitude and not timed. 


\subsection{New Design Simulation:}

With this chosen approach to logic circuitry, switches and switch drivers, a new simulation could be performed. See Appendix B for a full schematic. Figure 4-13 depicts the new switch signals with the analog control logic. They are not identical to the timed signals from the previous investigation, but they serve the same purpose and act similarly. The functionality of reducing the voltage across the MOSFET is more important than following the same exact pattern. An important note about this simulation is that because of the component models available, performance may not match perfectly but it serves the purpose of validating function and feasibility. Below the switch signals, in Figure 4-14, are the stack voltages. The voltages show whether or not the switches are properly diverting current, and we can see although they are not as ideal as the voltage controlled switch in the previous investigation, the functionality is still there, with the LED stack voltage across the switch when it is off, and only a few hundred millivolts at the most appears across it when off (indicating a short across the stack).

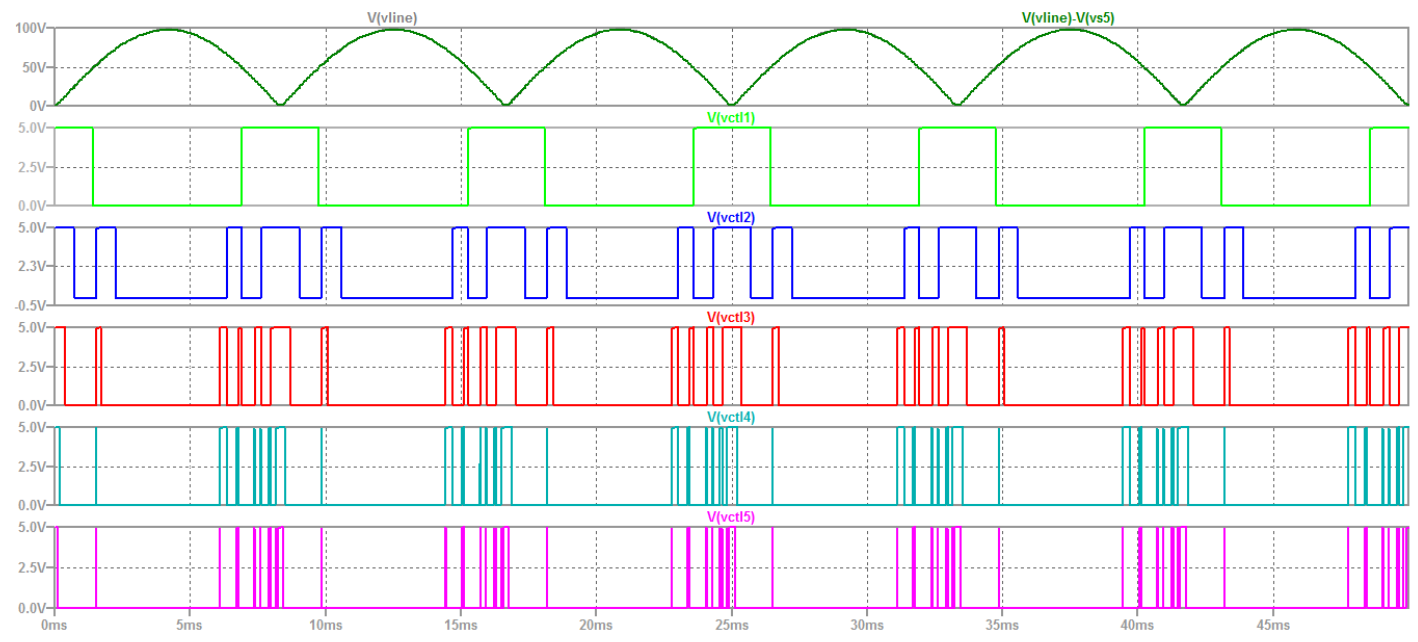

Figure 4-13: New simulation switch signals. From top to bottom: rectified line voltage and total LED stack voltage, switch signal 1, switch signal 2, switch signal 3, switch signal 4, and switch signal 5. Note that switch signals are inverted logic (a low signal means that LED stack is on). 


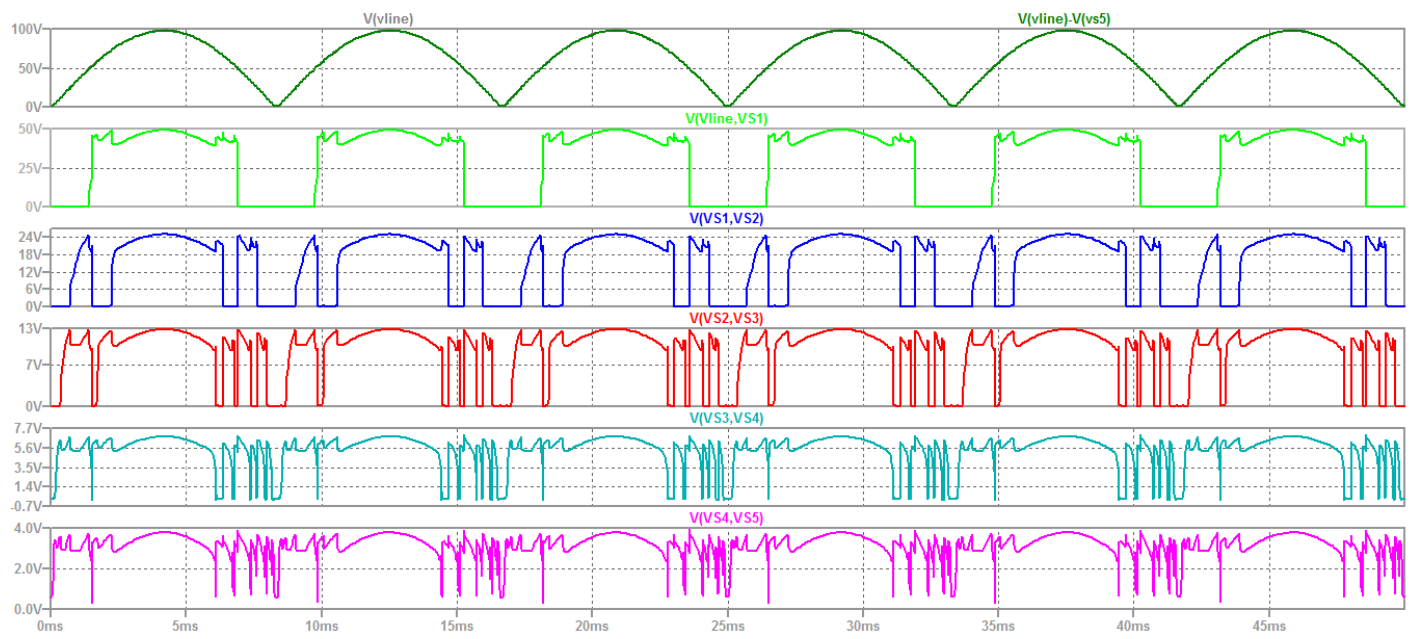

Figure 4-14: Stack voltages. From top to bottom: Rectified line voltage and total LED stack voltage, voltage across stack 1 , voltage across stack 2 , voltage across stack 3 , voltage across stack 4, voltage across stack 5.

Similarly, we can also see how the switches are directing current by looking at the stack currents. Figure 4-15 shows how the total branch current is divided and shared between the different LED stacks. The tradeoff of increasing efficiency in this way is that the current becomes less sinusoidal as seen in Figure 4-16.

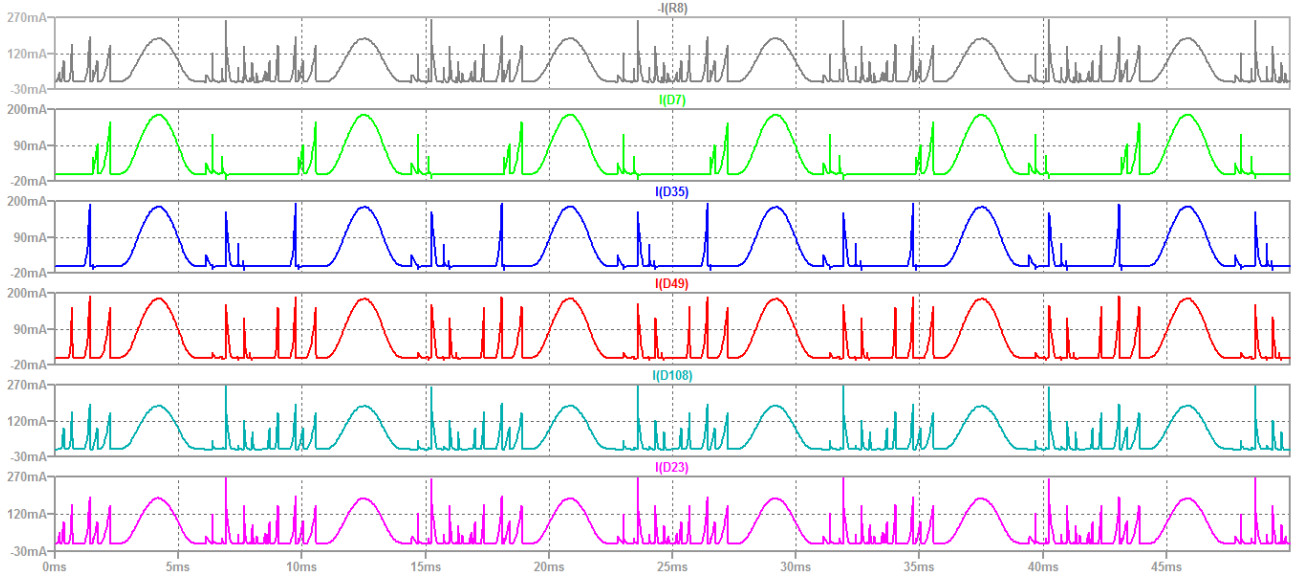

Figure 4-15: Stack currents. From top to bottom: rectified line current, stack current 1, stack current 2, stack current 3 , stack current 4 , stack current 5. 


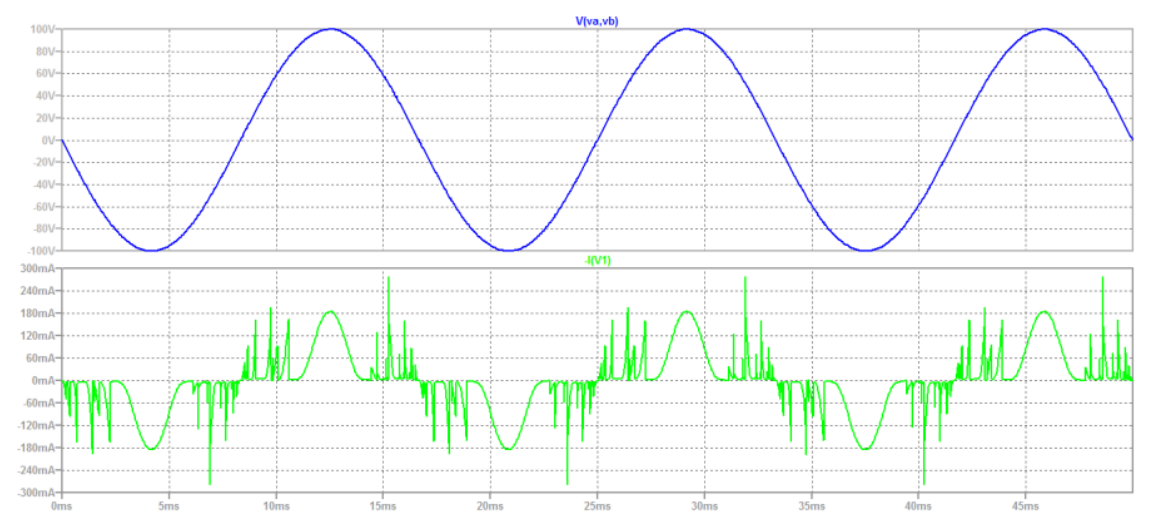

Figure 4-16: Input voltage (top) and input current (bottom).

Table 4-4 summarizes the power inputs and outputs of the new system. The efficiency is the main goal of this project, and there is only a small decrease in efficiency going from the ideal switches and logic to the analog logic and PNP switches. MOSFET loss is not dominant, also mirroring the previous simulation. With input current THD measured, it is obvious how much this has been traded for efficiency's sake.

Table 4-4: Summary of power use in new simulated system.

\begin{tabular}{|c|c|}
\hline $\mathbf{P}_{\text {in }}$ & $4.156 \mathrm{~W}$ \\
\hline $\mathbf{P}_{\text {out }}$ & $3.801 \mathrm{~W}$ \\
\hline $\mathbf{P}_{\text {MOS }}$ & $236.3 \mu \mathrm{W}$ \\
\hline $\mathbf{P}_{\text {RS }}$ & $12.04 \mathrm{~mW}$ \\
\hline $\mathbf{P}_{\text {RECT }}$ & $80.83 \mathrm{~mW}$ \\
\hline $\mathbf{P s W}_{\text {sW }}$ & $13.41 \mathrm{~mW}$ \\
\hline $\boldsymbol{\eta}$ & $91.5 \%$ \\
\hline Power Factor & 0.75 \\
\hline Input Current THD & $74 \%$ \\
\hline
\end{tabular}

\section{Chapter 5 : HARDWARE CONSTRUCTION, TEST, AND RESULTS}

\subsection{Component Selection:}

The LTSPICE simulation used to design the system employs models of real components, but many of the main parts are obsolete, so suitable replacements were chosen. Table $5-1$ shows the major parts of the system with their necessary and actual ratings. One of the major constraints of the system was finding LEDs with a rating above a couple hundred milliamps with a voltage drop that matched the simulation, and in a package that could be hand-soldered. Once this was chosen to be the Cree MLEAWT-A1, with a current rating of $500 \mathrm{~mA}$ and a typical 
forward drop of $3.2 \mathrm{~V}$, the rest of the main power path was chosen to meet this same current specification.

Table 5-1: Main power path component ratings.

\begin{tabular}{|c|c|c|c|c|}
\hline $\begin{array}{c}\text { System } \\
\text { Component }\end{array}$ & $\begin{array}{c}\text { Chosen Part } \\
\text { Number }\end{array}$ & $\begin{array}{c}\text { Maximum } \\
\text { Voltage } \\
\text { (worst-case) }\end{array}$ & Voltage Rating & Current Rating \\
\hline LEDs & MLEAWT-A1 & & & $500 \mathrm{~mA}$ \\
\hline Bridge Rectifier & CBRHDSH1 & $100 \mathrm{~V}$ & $200 \mathrm{~V}$ & $1 \mathrm{~A}$ \\
\hline PNP Switches & MMBT5401L & $\sim 60 \mathrm{~V}$ & $150 \mathrm{~V}$ & $500 \mathrm{~mA}$ \\
\hline $\begin{array}{l}\text { Current } \\
\text { Blocking } \\
\text { Diodes }\end{array}$ & SBR1U150SA & & $150 \mathrm{~V}$ & $1 \mathrm{~A}$ \\
\hline $\begin{array}{c}\text { Linear } \\
\text { Regulator N- } \\
\text { type MOSFET }\end{array}$ & PSMN057 & $100 \mathrm{~V}$ & $200 \mathrm{~V}$ & $39 A$ \\
\hline $\begin{array}{c}\text { Source } \\
\text { Resistor, } 2 \Omega\end{array}$ & & & $\begin{array}{c}\text { Power rating } \\
1 / 2 \mathrm{~W}\end{array}$ & $500 \mathrm{~mA}$ \\
\hline
\end{tabular}

A full bill of materials can be found in Appendix D. The components in Table 5-1 are the main power components, whereas the control circuitry was chosen differently. The Microchip MCP65R41T comparator was chosen because it could operate at 5V supply, generated its own reference voltage (thus saving routing PCB traces for a reference divider and likely better stability), and was in a package that could be hand-soldered. Any other active components were chosen to meet the same specifications as the simulation. Assorted passive components (largely resistors) did not carry much power and such 1/8-1/4W ratings were acceptable, in an 0805 surface-mount package.

\subsection{PCB Design and Construction:}

The goal of this project is to build a functioning prototype that demonstrates the conclusions from the previous simulation investigation in hardware [21]. Thus, cost and size were not significant considerations for this prototype. The goal of the PCB design was to build a functional device that could be easily constructed, measured, and handled.

Easier construction was accomplished by selecting components in packages that could be hand-soldered with solder paste and a heat gun. To assist with measurements and troubleshooting, test point loops were added all over the board to allow all important signals and voltages to be measured quickly. Sense resistors were also added in series with the LEDs to 
allow for an output power measurement. Overall the design was meant to be not excessively spread out, but accessible, and with repeated sections (LED stacks and controls) laid out identically to allow for fast troubleshooting. Figure 5-1 shows a 3D rendering of the final PCB design.

Since this system operates at a high voltage but relatively low current and power, trace width was not a significant issue. The main power path has $1 \mathrm{~mm}$ traces, the five-volt supply path has $0.5 \mathrm{~mm}$ traces, and low-power runs use a $0.25 \mathrm{~mm}$ trace width. The board is two-sided, with the entire bottom of the board as a poured ground plane, and all signals routed on the top side. A custom footprint was designed for the Cree LEDs, with dimensions from the recommendation in the LED datasheet. Banana plugs are used for the AC and DC supply voltages, and the board is suspended off of the lab bench by four $5 / 8$ " hex standoffs.

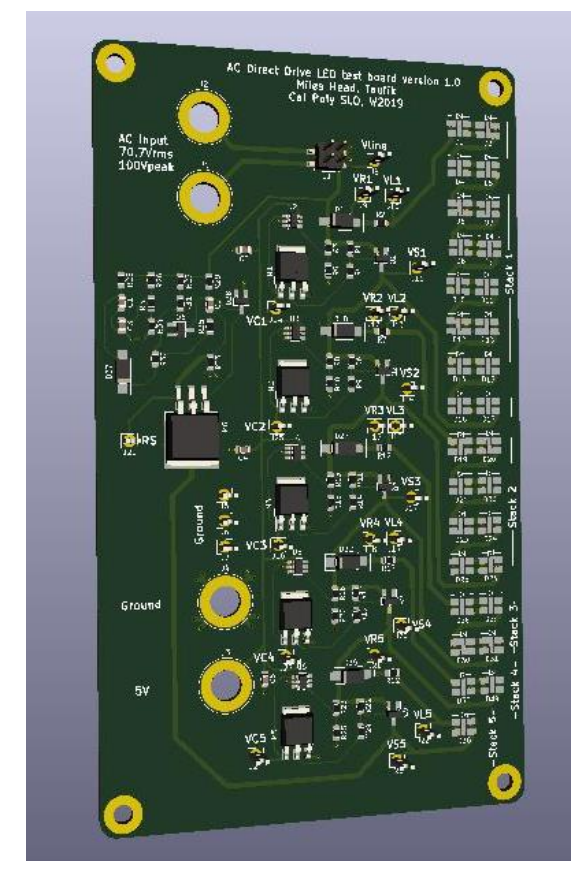

Figure 5-1: $3 D$ rendering of final $P C B$ design.

Populating the PCB was relatively simple. Solder paste and a heat gun were used to attach all components. All footprints lined up as expected, and once the board was populated, its proper operation was ready to be validated. The completed board is seen in Figure 5-2. 


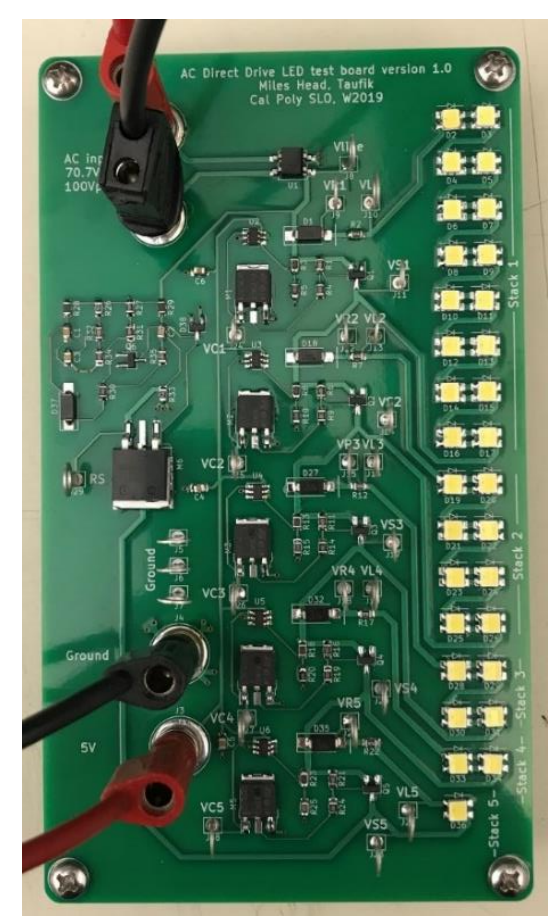

Figure 5-2: Populated PCB ready to be validated.

\subsection{Measurement Methodologies:}

The main measurements collected were efficiency, power factor, current THD, flicker index, and DC supply power. Additional plots of the stack voltages and control signals were collected to verify proper operation and compare to simulation. Figure 5-3 shows the general bench setup for testing of the system. All measurements were taken after the system reached steady-state. All scope data were collected with the Fluke 190 series power scope meter.

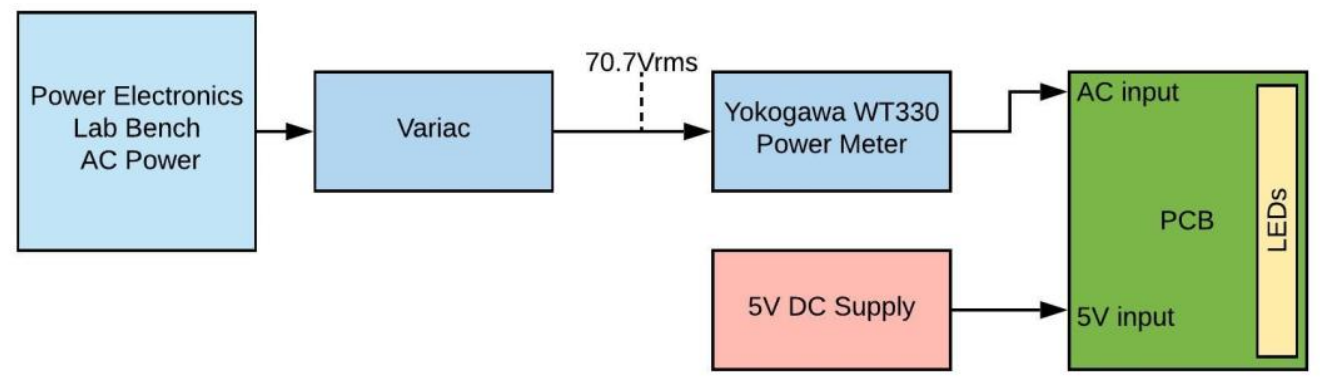

Figure 5-3: General lab bench setup for measurement of the system. 
The setup in Figure 5-3 was used to measure power factor, THD, and input power. The Yokogawa WT330 can calculate THD up to the $50^{\text {th }}$ harmonic for input current and voltage. In this case, THD of the input current is calculated.

Efficiency is calculated as the ratio of output and input average powers. Input power can be easily read from the Yokogawa WT330, but output power must be measured more carefully. Output power is defined as the sum of the power of all LEDs, measured separately for each stack. This is accomplished as in Figure 5-4, where the sense resistor is removed from a stack to place the Yokogawa ammeter in series, while the voltmeter measures across the stack. This is repeated for each stack, and the totals are summed to calculate efficiency. It is important to set the Yokogawa WT330 to a crest factor of 6 to allow power measurements as small as $18.75 \mathrm{~mW}$. This is not an issue for most stacks, but the fifth one (with a single LED) has output power approaching this value.

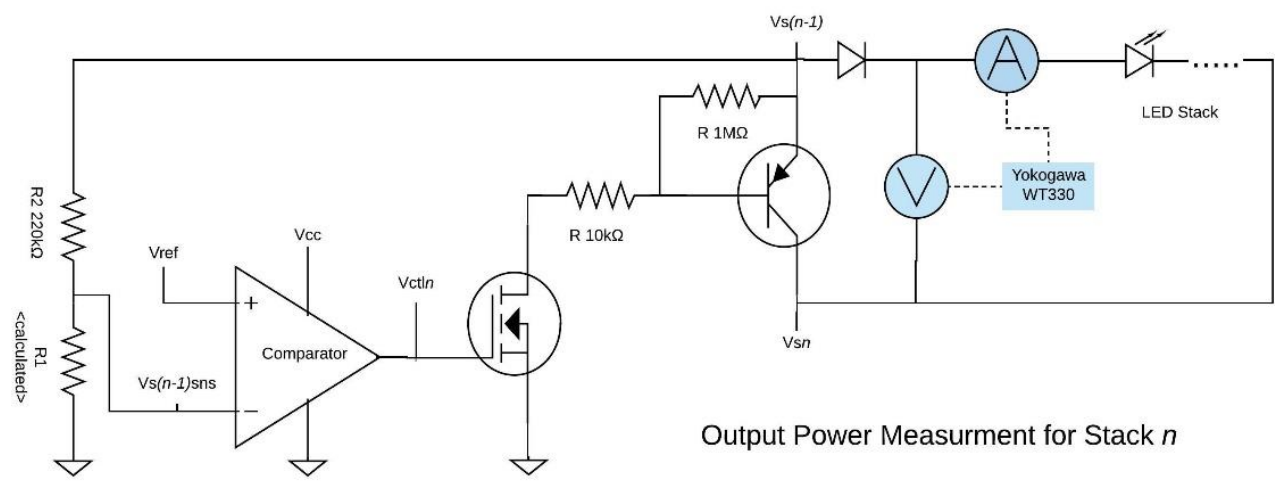

Figure 5-4: Output power measurement for each stack.

The DC supply power was simply calculated by measuring the current from the supply with a multimeter and multiplying by the DC voltage.

For this project, flicker index will be calculated rather than flicker percentage. Since the LEDs are off for a finite time at each half cycle, it is guaranteed that the design has $100 \%$ flicker according to the definition. But as outlined before, neither metric accounts for human perception. Something that has $100 \%$ flicker in the right way may not appear to flicker to a person, this is just an easy metric to compare designs. Using the OPT101P photodiode and transimpedance 
amplifier, similar to the method outlined in an application note from Richtek Technology [23]. The circuit in Figure 5-5 was implemented in a box, seen in Figure 5-6. The output of the diode/amplifier IC is viewed on an oscilloscope to capture the relative brightness over time of the light source. The IC was centered approximately seven inches above the LEDs, as in Figure 5-7. Also, as in the application note, three sheets of printer paper were placed over the sensor to reduce the direct beam from the light. The distance was adjusted such that the entire output range was used but no clipping occurred. All lights in the room were shut off and the blinds were pulled for close to complete darkness. The flicker index was calculated using oscilloscope data and MATLAB. The script used is in Appendix E.

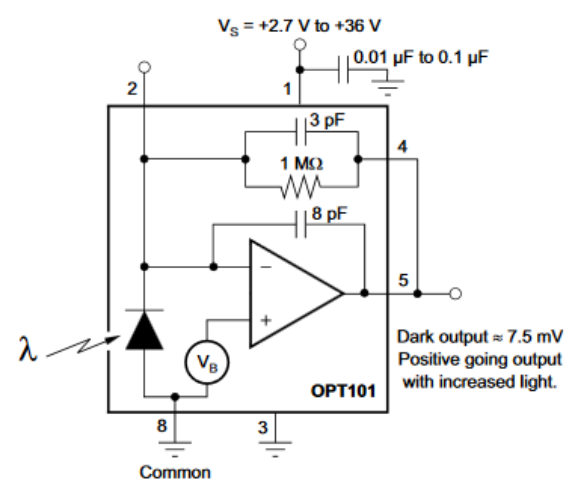

Figure 5-5: Application circuit for the OPT101 [24].

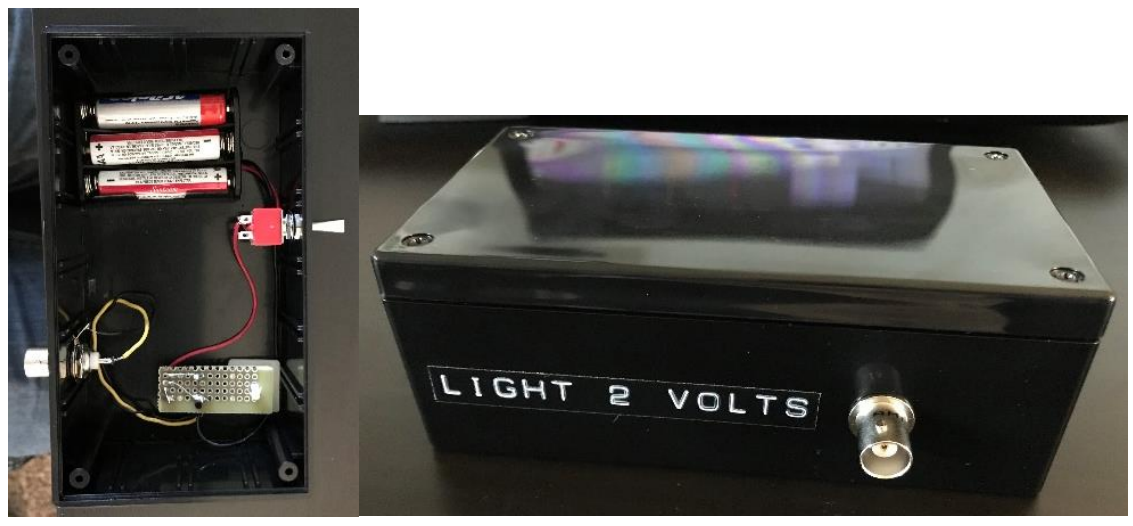

Figure 5-6: Final flicker-measuring box. 


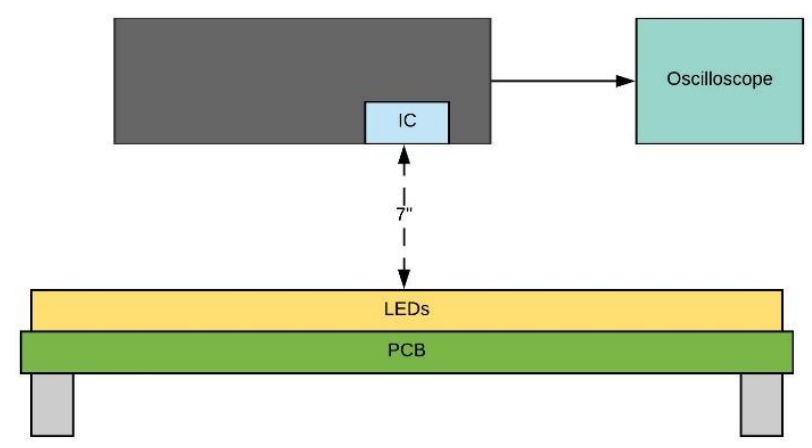

Figure 5-7: Flicker measurement test setup.

\subsection{Measurement Results:}

The first step in measuring the physical system was to validate if it was operating as intended, similar to the simulation. As stated previously, the simulation is a useful proof-ofconcept but may not be identical to the physical system, due to different parts/models used. The main plots that validate proper operation are the control signals and the stack voltages. Figure 58 shows the composited control signals, with the rectified line voltage to show where they line up in a cycle. These signals look as expected and indicate the control circuitry is largely operating as intended. Recall that the logic is inverted, so a logical low in this plot means that LED stack is active. Figure 5-9 shows the LED stack voltages, which are very close to their simulated counterparts. This plot along with Figure 5-10, the voltage across the linear regulating MOSFET and resistor, shows that the overall goal of minimizing MOSFET loss is attained by the physical analog control circuitry. 


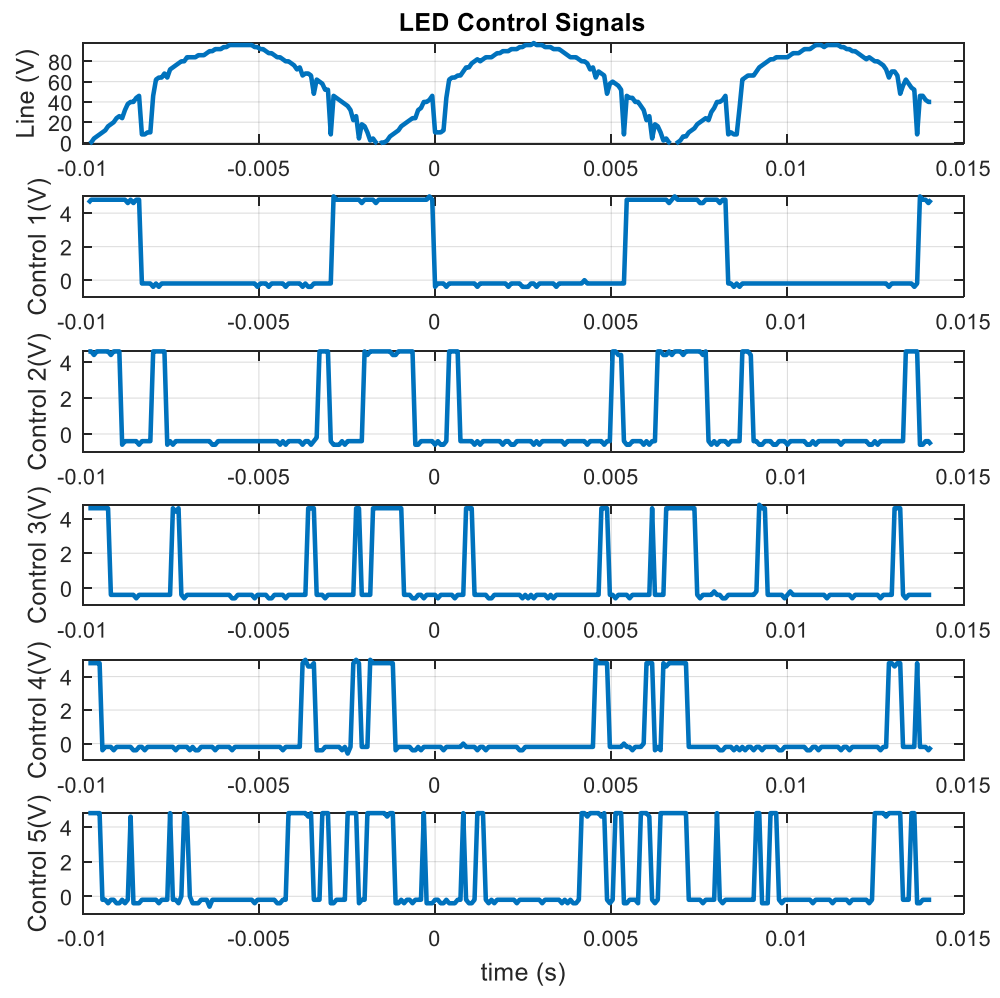

Figure 5-8: Measured LED control signals.

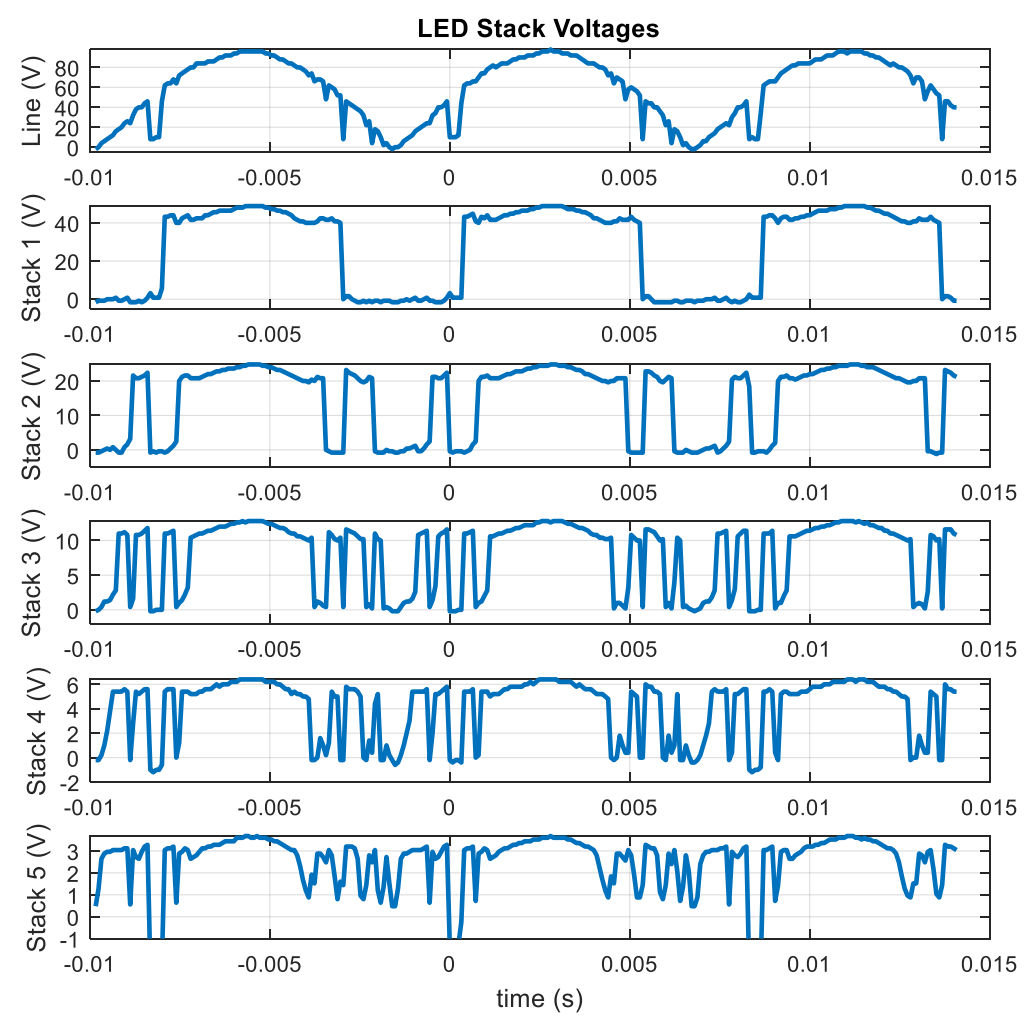

Figure 5-9: Measured stack voltages. 

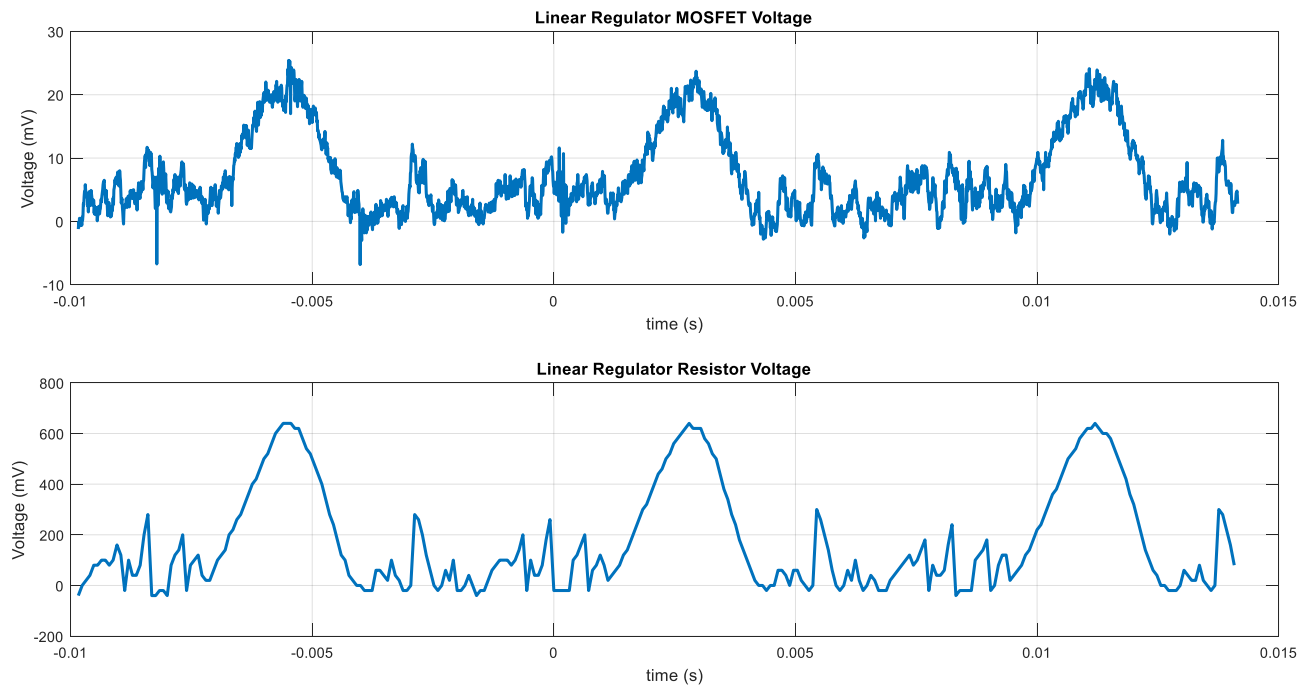

Figure 5-10: Linear regulator MOSFET and resistor voltages.

The most important aspect of this experiment was to validate that in an AC direct-drive LED system, there is a tradeoff between the efficiency and the input characteristics of the system. Table 5-2 compares each stack output power, input power, and efficiency for the simulated and measured systems. Although the output power is different in the measured system, largely due to different I-V characteristics of the LEDs used, the efficiency is very close. Table 5-3 shows that the 5V DC portion of the circuit dissipates very little power, with and average current draw of $42 \mu \mathrm{A}$ and power of $210 \mu \mathrm{W}$. Figure $5-11$ shows a thermal image of the system during operation, where the LEDs are warm as expected but the linear regulating MOSFET and resistor are not significantly hot, showing they are dissipating little power.

Table 5-2: Simulated and measured efficiency of system.

\begin{tabular}{|c|c|c|}
\hline & $\begin{array}{c}\mathbf{P}_{\text {out }} \\
\text { Simulation (W) }\end{array}$ & $\begin{array}{c}\mathbf{P}_{\text {out }} \\
\text { Measured (W) }\end{array}$ \\
\hline Stack 1 & 1.9195 & 4.16200 \\
\hline Stack 2 & 0.9399 & 2.26500 \\
\hline Stack 3 & 0.5246 & 1.19400 \\
\hline Stack 4 & 0.276 & 0.62410 \\
\hline Stack 5 & 0.1408 & 0.30310 \\
\hline Total & 3.8008 & 8.54820 \\
\hline P $_{\text {in }}$ & 4.156 & 9.05 \\
\hline Efficiency & $91.45 \%$ & $94.46 \%$ \\
\hline
\end{tabular}


Table 5-3: Power from the DC supply used for this experiment.

\begin{tabular}{|c|c|}
\hline$I_{D C}(\mu A)$ & 42.0 \\
\hline$V_{D C}(V)$ & 5 \\
\hline$P_{D C}(\mu W)$ & 210.0 \\
\hline
\end{tabular}

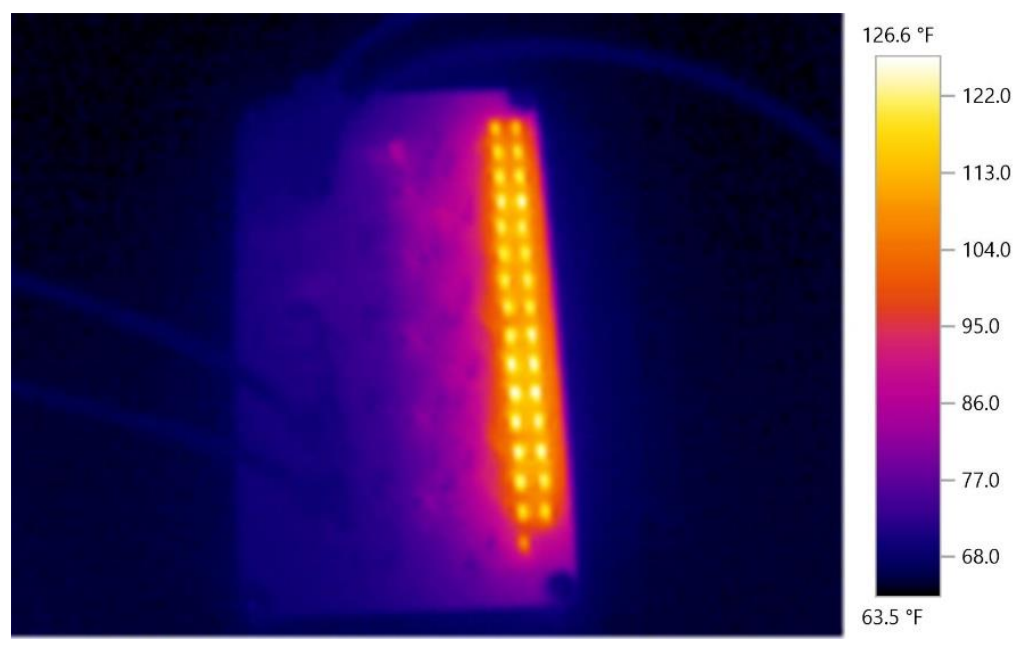

Figure 5-11: Thermal image of the AC LED system during operation.

Table 5-4 summarizes the input characteristics of the final system. The measured THD up to the $50^{\text {th }}$ harmonic is $58.9 \%$, better than the simulation but still poor as most systems go. The power factor is acceptable at 0.858 . With an increased efficiency compared to most AC LED systems, from the simulation we would expect a poorer input characteristic, and we do see that here. This measurement confirms this tradeoff observed in simulation.

Table 5-4: Input characteristics of measured system.

\begin{tabular}{|c|c|c|}
\hline & Simulation & Measured \\
\hline Input Current THD order $=\mathbf{1 0}$ & $74.05 \%$ & $55.43 \%$ \\
\hline Input Current THD order $\mathbf{5 0}$ & $82.00 \%$ & $58.90 \%$ \\
\hline Power Factor & 0.75 & 0.858 \\
\hline
\end{tabular}

Figure 5-12 shows the output of the flicker measuring tool, along with the average brightness value used to calculate flicker index. The MATLAB code that processes this data simply divides the scope data into the curve above and below the average line, determines the area under the curves, and then uses the flicker index equation to calculate a value. In this case, a flicker index of 0.6068 is achieved. Zero represents no flicker while a one represents the most 
flicker, so this is just above halfway. This does not correspond to human perception however, and the lights does not visibly flicker to the human eye. Figure 5-13 shows a fast Fourier transform of the collected signal, showing that the most significant frequency components are at DC and multiples of $120 \mathrm{~Hz}$, outside the range of $0^{+}-80 \mathrm{~Hz}$ where flicker is most troublesome for most people [18].

This conclusion aligns with the previous findings that as the efficiency is increased by reducing voltage dropped on the regulator, the current contains more harmonics. This current is what is driving the LEDs, so increased flicker is to be expected as well. This could be a problem or not, depending on application, but is a valid tradeoff of this design.

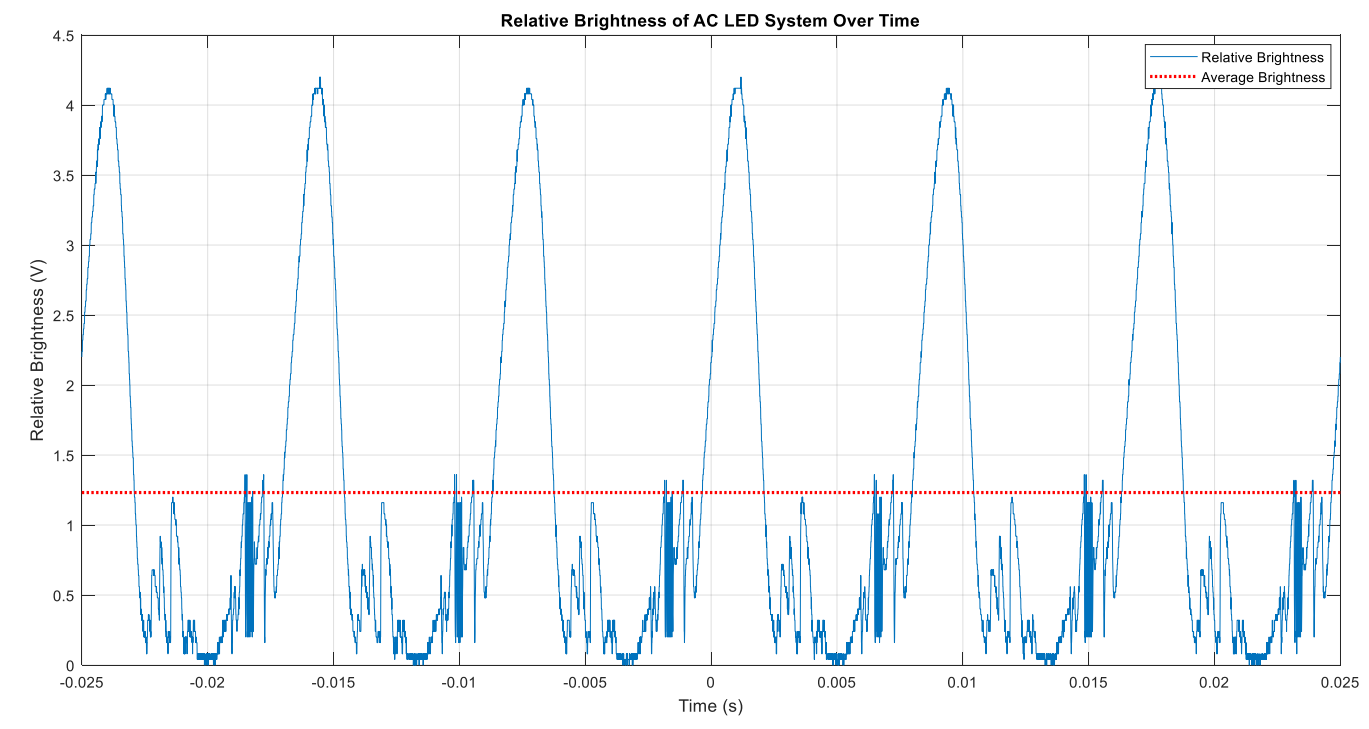

Figure 5-12: Output from flicker measuring tool used to calculate flicker index. 


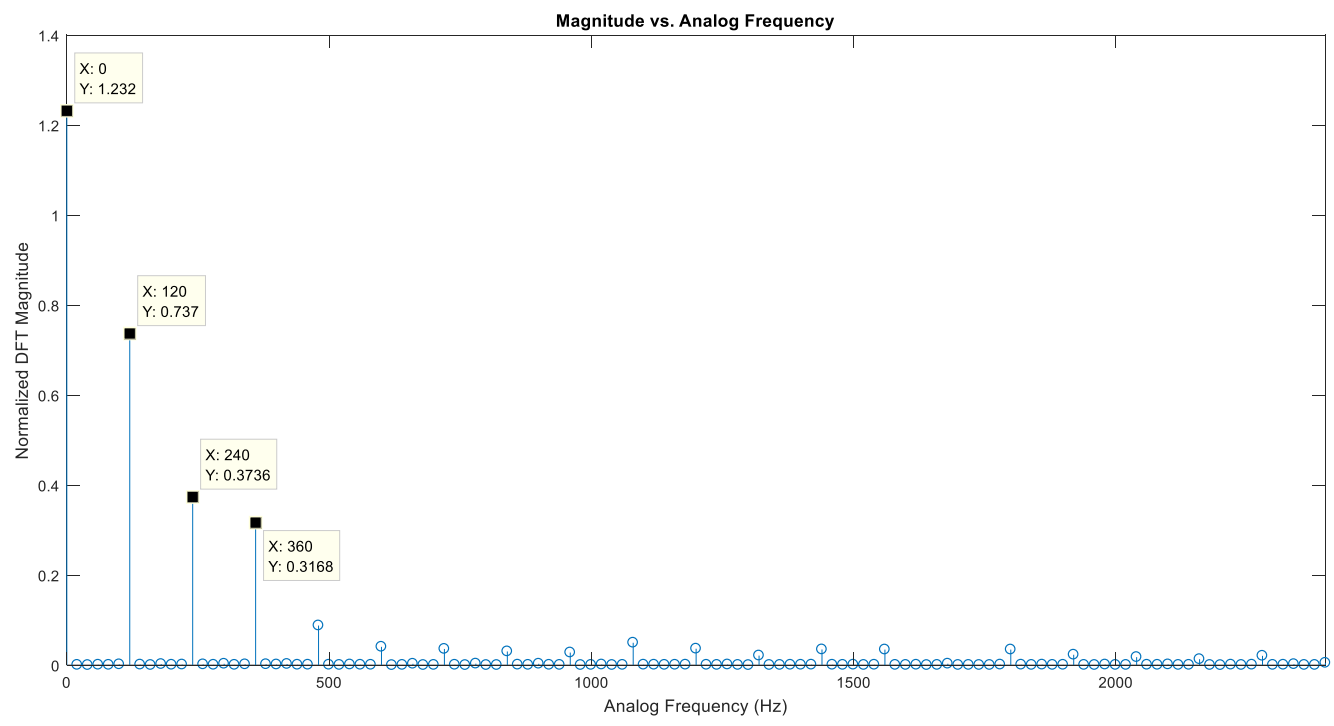

Figure 5-13: FFT of flicker signal obtained in the lab.

One issue that would likely be addressed in a second revision of this design is a part of the cycle where the line voltage and control signals oscillate for a short time, circled in Figure 514. When the largest LED stack (stack one) is turning on, it briefly pulls the line voltage down. This in turn puts the sense voltage below the threshold, turning the stack back off. The line recovers, turning the stack back on. This repeats five to eight times over a period of about $350 \mu$ s. This can be seen in Figures 5-15, 16, and 17 showing the line voltage and stack one voltage, stack one control, and stack one sense respectively. This error does not affect the overall functionality of this prototype or its ability to demonstrate what was seen in simulation but could be helped in a second revision. The best solution would likely be to raise the threshold for the first stack slightly by lowering the sense resistor, and to add hysteresis to the comparators used for control to prevent this effect. This is similar to how debouncing is done when using a mechanical switch to interact with a microcontroller.

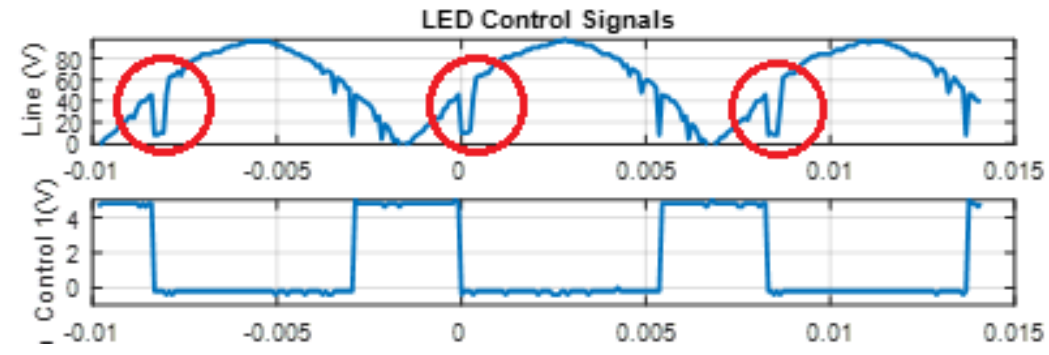

Figure 5-14: Portion of line/control waveforms under question (circled). 

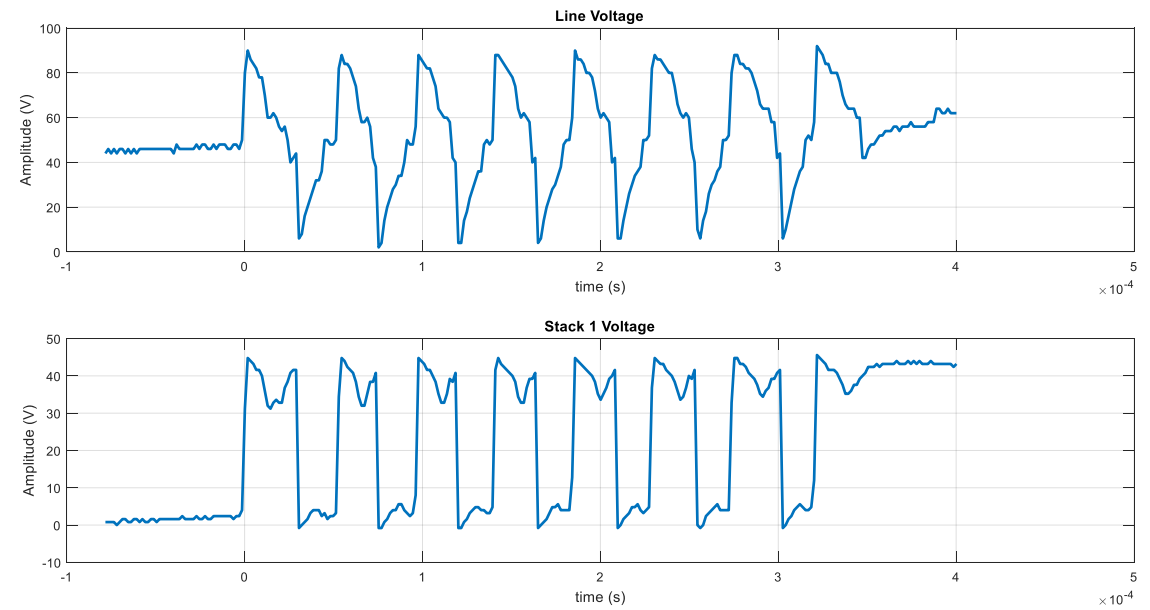

Figure 5-15: Line voltage and stack 1 voltage during short period of oscillation.
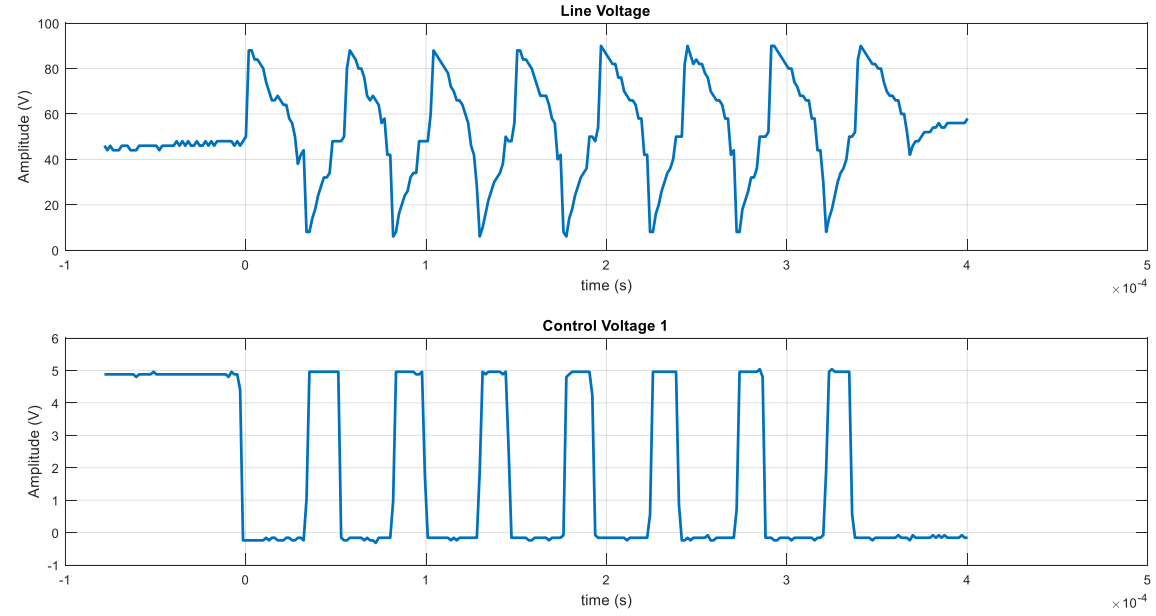

Figure 5-16: Line voltage and control voltage 1 during short period of oscillation.
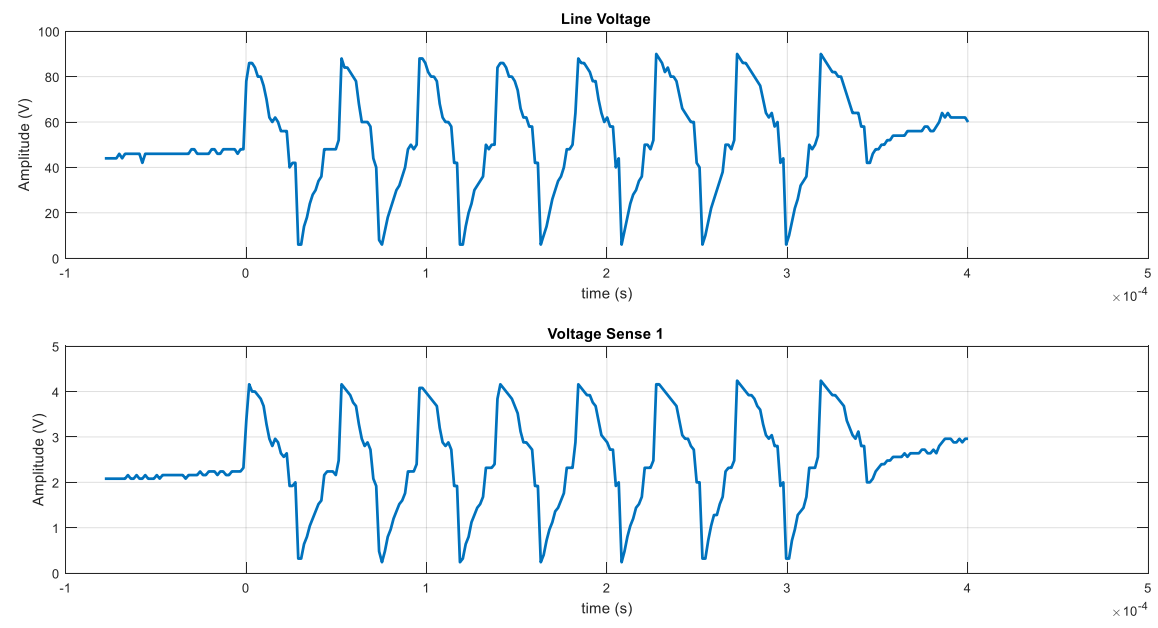

Figure 5-17: Line voltage and sense voltage 1 during short period of oscillation. 


\section{Chapter 6 : CONCLUSION}

The goal of this project was to design a scaled-down physical AC LED direct drive system to validate the conclusions of methods of improving efficiency from the previous investigation. AC direct drive systems eliminate costly and heavy filtering capacitors and magnetics from traditional DC-DC based LED solutions. They also better match LED lifetime, since there are no input capacitors to fail. The previous investigation found that by increasing the number of stacks of LEDs and switching them in a way that minimized voltage dropped across the linear regulating MOSFET, efficiency of an AC LED system could be increased with the tradeoff of worsened input characteristic (current THD). This project found that this conclusion is physically realizable, with a final efficiency of $94.46 \%$ and an input current THD of $58.9 \%$.

This result was achieved by taking the previous investigation's final design as a starting point and replacing components with currently available options. The most crucial step was translating piecewise linear control voltages and ideal switches into analog logic and real switches. The final version uses a set of comparators and sense resistors to determine when a given LED stack should be on for a simple, analog control solution. The switches used are PNP

BJTs, with their bases driven from N-type MOSFETs. The MOSFETs can be driven from standard logic voltages from the comparators, and the MOSFETs sink current, activating the PNP switches as needed. This eliminates costly and complex high-side driving ICs, since the LED stacks are not ground-referenced. This project uses a dedicated five-volt supply for the comparator logic.

Once the system could be physically realized, the assembled version was used to measure efficiency, power factor, current THD, flicker index, and DC supply power. Additional plots of the stack voltages and control signals were collected to verify proper operation and compare to simulation. The final efficiency of $94.46 \%$ at an output power of about $9 \mathrm{~W}$ is very close to the simulated value. An input current THD of $58.9 \%$ is hardly ideal but it clearly shows the tradeoff made for this improved efficiency. The power factor of the system is 0.858 , which is not incredible but is likely acceptable. Increasing the efficiency had little impact on the power factor, since the input voltage and current remain close to in-phase and vaguely sinusoidal. The flicker index of the system is 0.6068 , which is also not ideal but since flicker index does not 
represent how humans see flicker, it does not tell the full story. The FFT of the light brightness plot shows the strongest peaks at DC and $120 \mathrm{~Hz}$, which are both outside of the most irritating flicker range for humans. No flicker is visible when using the light under normal conditions.

To improve this design in the future, the control logic should be modified with hysteresis on each comparator, to prevent any ringing from the line voltage being pulled down briefly by a stack turning on. The next steps with this design, should someone want to move forward would be to design in a 5V DC supply for the control logic, so the entire system runs only on wall power. The next step would be to scale the system back up to accommodate either $120 \mathrm{~V}$ or $240 \mathrm{~V}$ wall power. At that point, the system could be used if it were desired. The tradeoff between efficiency and input current THD is likely not a practical one for designing a commercial product, but this experiment shows it can be done and what results. 


\section{REFERENCES}

[1] D. Clark, "What's energy efficiency and how much can it help cut emissions?," The Guardian, 8 June 2012.

[2] U. E. I. Administration, "What is Energy? Explained," US EIA, 30 May 2017. [Online]. Available: https://www.eia.gov/energyexplained/index.cfm?page=about_home. [Accessed 31 January 2018].

[3] U. E. I. Administration, "Many states have adopted policies to encourage energy efficiency," 3 August 2017. [Online]. Available:

https://www.eia.gov/todayinenergy/detail.php?id=32332. [Accessed 31 January 2018].

[4] U. E. I. Administration, "FAQ: How much electricity is used for lighting in the United States?," 23 May 2017. [Online]. Available:

https://www.eia.gov/tools/faqs/faq.php?id=99\&t=3. [Accessed 31 January 2018].

[5] U. E. I. Administration, "What's New in How We Use Energy at Home: RECS 2015," 31 May 2017. [Online]. Available:

https://www.eia.gov/consumption/residential/reports/2015/overview/index.php?src=\%E2\% 80\%B9\%20Consumption\%20\%20\%20\%20\%20\%20Residential\%20Energy\%20Consumpt ion\%20Survey\%20\%28RECS\%29-b1. [Accessed 31 January 2018].

[6] U. E. I. Administration, "Trends in Lighting in Commercial Buildings," 17 May 2017. [Online]. Available: https://www.eia.gov/consumption/commercial/reports/2012/lighting/. [Accessed 31 January 2018].

[7] U. E. I. Administration, "LED light bulbs keep improving in efficiency and quality," 4 November 2014. [Online]. Available:

https://www.eia.gov/todayinenergy/detail.php?id=18671. [Accessed 31 January 2018].

[8] N. Consulting, "EIA Technology and Forecast Updates, Residential and Commercial Building Technologies," US Energy Information Administration, Washington, DC, 2016.

[9] L. L. P. M. Yuan Gao, "An AC Input, Switching Converter Free, LED Driver with LowFrequency Flicker Reduction," IEEE Journal of Solid-State Circuits , vol. 52, no. 5, pp. 1424-1435, 2017.

[10] F. Mirand, "ELectronics Weekly," 19 April 2016. [Online]. Available: https://www.electronicsweekly.com/news/why-not-direct-ac-drive-your-led-string-2016-04/. [Accessed December 2017].

[11] X.-Q. L. H.-S. H. H.-X. D. Cong Liu, "Sectional LED Driver for Optimised Efficiency in Lighting Applications," IET Power Electron, vol. 9, no. 4, pp. 825-835, 2016.

[12] O. Semiconductor/Fairchild, Fairchild FL77944 Datasheet, ON Semiconductor, 2016.

[13] T. Instruments, TPS9211 Datasheet, Texas Instruments, 2014.

[14] J.-J. S. K.I. Hwu, "Dimmable AC LED Driver Based on Series Drive," Journal of Display Technology, vol. 12, no. 10, pp. 1097-1106, 2016. 
[15] C.-T. R. Changbyung Park, "Filter-free AC Direct LED Driver with Unity Power Factor and Low Input Current THD Using Binary Segmented Switched LED Strings and Linear Current Regulator," Long Beach, CA, USA, 2013.

[16] A. J. Wilkins, "The Conversation," 27 July 2017. [Online]. Available: http://theconversation.com/the-scientific-reason-you-dont-like-led-bulbs-and-the-simpleway-to-fix-them-81639. [Accessed 1 June 2018].

[17] AZO Materials, "A Guide to Measuring the Flicker of LEDs and SSL Using a SpectroColorimeter," 18 June 2015. [Online]. Available:

https://www.azom.com/article.aspx?ArticlelD=12161. [Accessed September 2018].

[18] D. J. Gaines, Temporal Light Artifacts, Philips, 2016.

[19] Y. Y. Chen, G. W. Chang and S. C. Lin, "A digital implementation of IEC 61000-4-15 flickermeter," in IEEE Power \& Energy Society General Meeting, 2015.

[20] S. P. Junsik Kim, "A Direct AC Driver with Reduced Flicker for Multiple String LEDs," JOURNAL OF SEMICONDUCTOR TECHNOLOGY AND SCIENCE, vol. 15, no. 3, pp. 390-397, 2015.

[21] M. Head, " Investigating Efficiency of AC Direct Drive of LED Lighting," California Polytechnic State University, San Luis Obispo, San Luis Obispo, 2018.

[22] Texas Instruments, TPS92411 Floating Switch for OffIne AC Linear Direct Drive of LEDs Datasheet, Dallas, Texas: Texas Instruments, 2014.

[23] Richtek Technology Corporation, How to measure light flicker in LED lamps, Richtek Technology, 2016.

[24] Texas Instruments, OPT101 Monolithic Photodiode and Single-Supply Transimpedance Amplifier, Texas Instruments , 2015.

[25] Texas Instruments, TPS92411/10, 50W, 120VAC LED Driver, Dallas, Texas: Texas Instruments, 2017. 


\section{APPENDICES}

A. Previous Investigation: Final Schematic

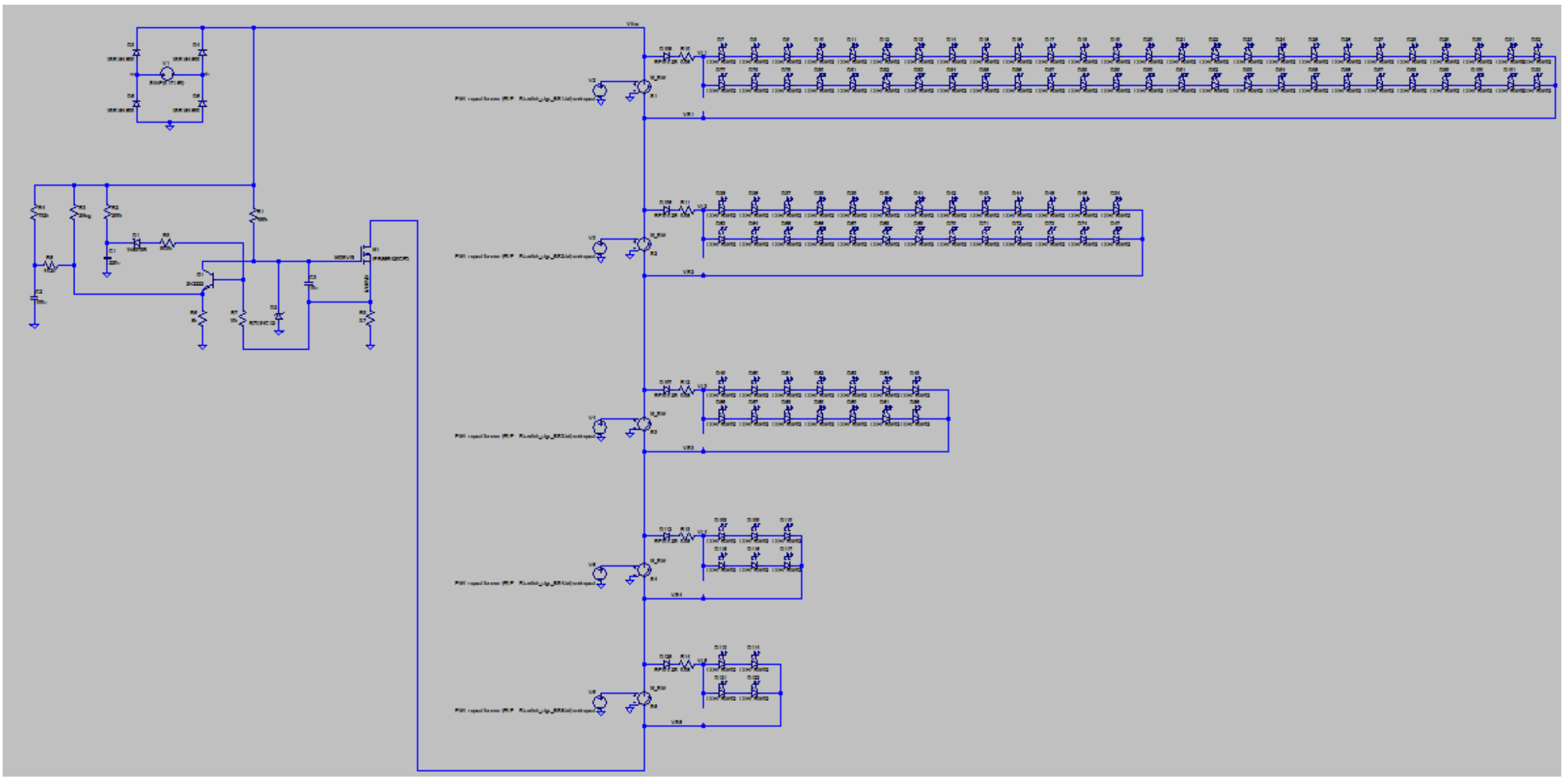




\section{B. Physical System: Final Simulation Schematic}

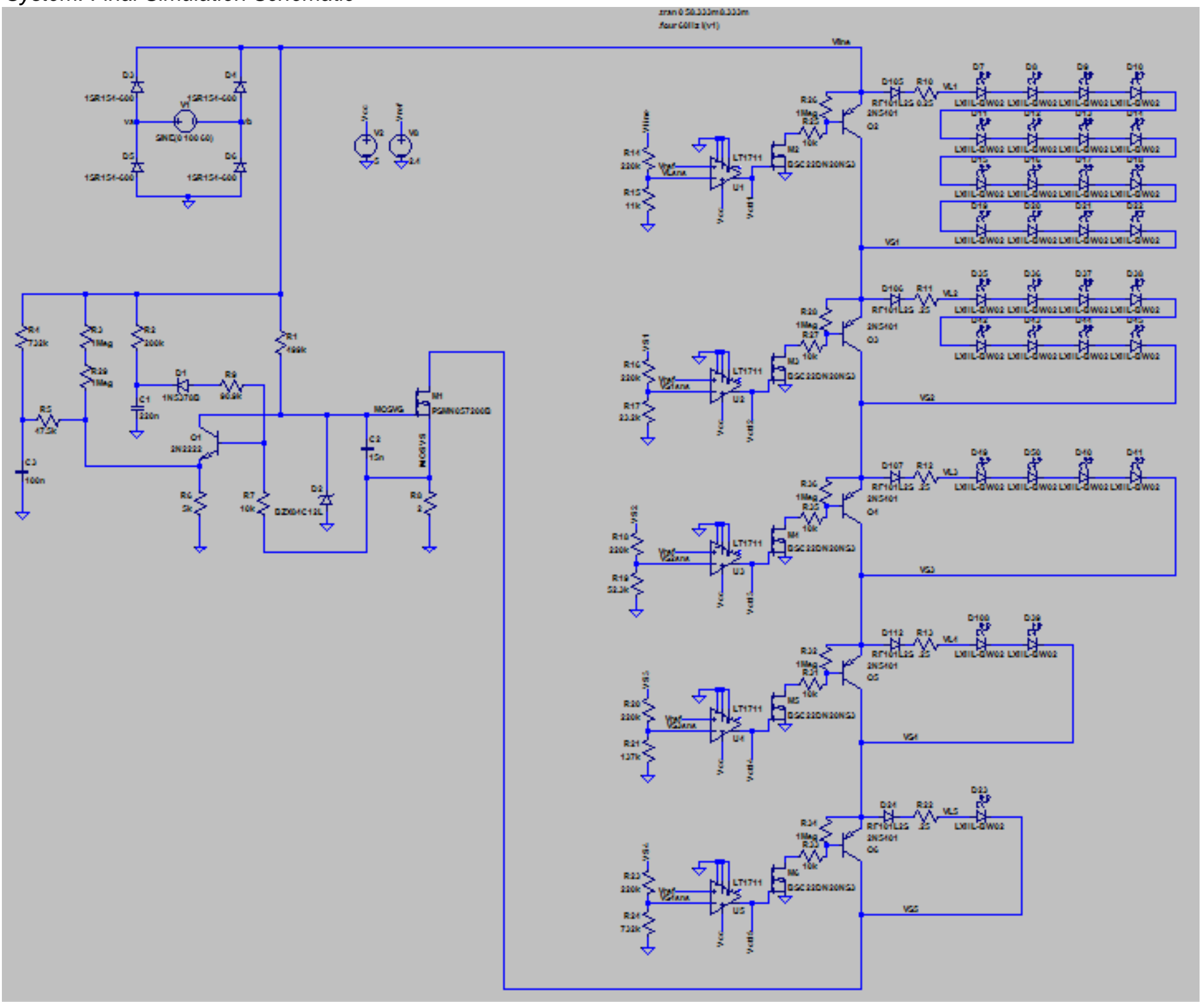




\section{Final Schematic for PCB}

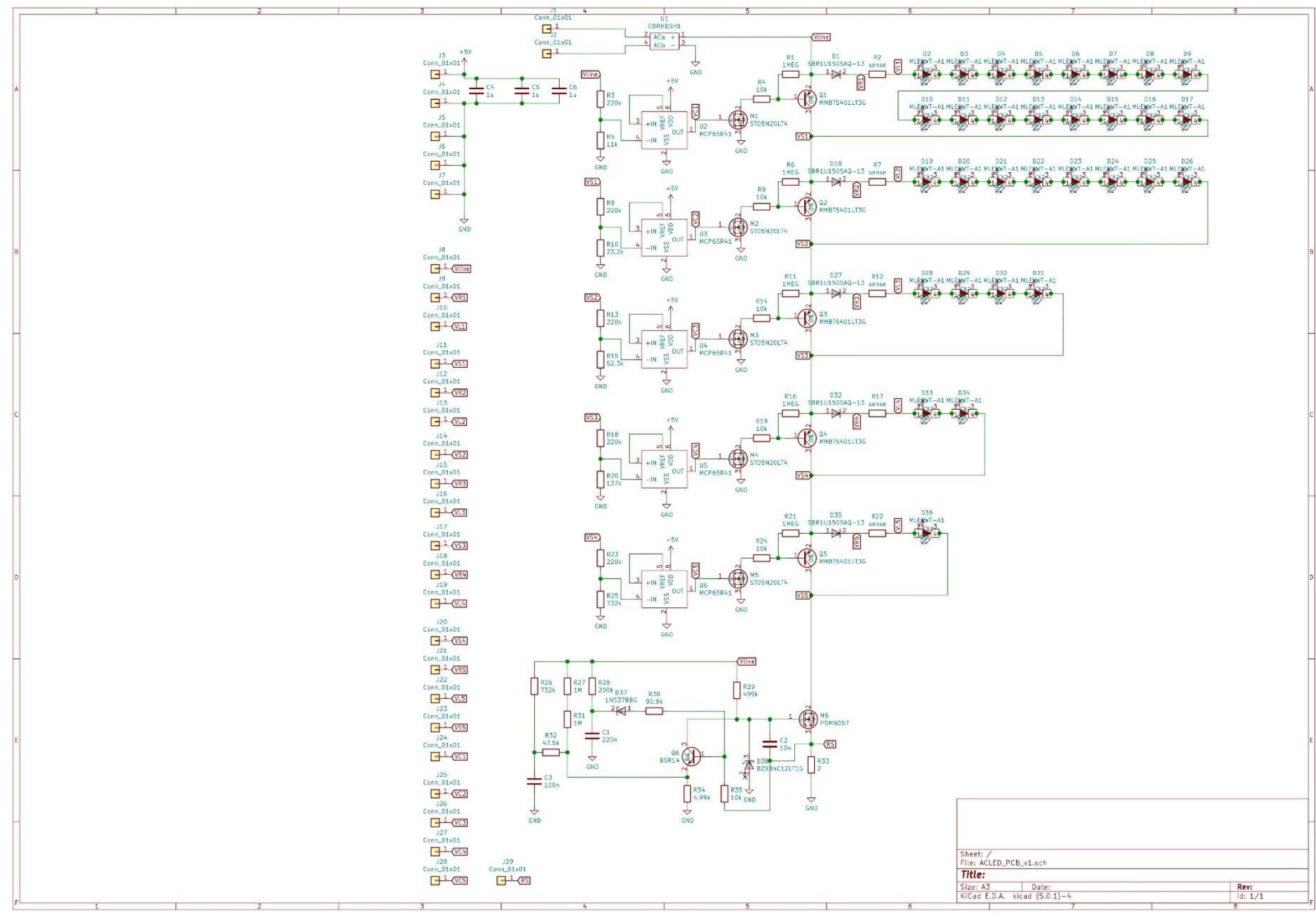


D. Bill of Materials

\begin{tabular}{|c|c|c|c|c|c|c|c|c|c|c|}
\hline Index & $\begin{array}{l}\text { Digikey Part } \\
\text { Number }\end{array}$ & $\begin{array}{l}\text { Manufacturer } \\
\text { Part Number }\end{array}$ & Description & Ref. Des. & Reference & Quantity & & Price & & Price \\
\hline 1 & $\begin{array}{c}\text { MCP65R41T- } \\
\text { 2402E/CHYCT-ND }\end{array}$ & $\begin{array}{l}\text { MCP65R41T- } \\
\text { 2402E/CHY }\end{array}$ & $\begin{array}{c}\text { IC COMPARATOR 2.4V } \\
\text { REF SOT-23-6 }\end{array}$ & U2-U6 & comparator & 5 & $\$$ & 0.44 & $\$$ & 2.20 \\
\hline 2 & $\begin{array}{l}\text { MLEAWT-A1-0000- } \\
\text { 0003E1CT-ND }\end{array}$ & $\begin{array}{l}\text { MLEAWT-A1- } \\
0000-0003 E 1\end{array}$ & $\begin{array}{l}\text { LED XLAMP COOL } \\
\text { WHITE 6500K 4SMD }\end{array}$ & $\begin{array}{c}\text { D2-D17, } \\
\text { D19-D26, } \\
\text { D28-D31, } \\
\text { D33-D34, } \\
\text { D36 }\end{array}$ & LEDs & 31 & $\$$ & 0.37 & $\$$ & 11.32 \\
\hline 3 & 1727-4774-1-ND & $\begin{array}{l}\text { PSMN057- } \\
200 \mathrm{~B}, 118\end{array}$ & $\begin{array}{l}\text { MOSFET N-CH } 200 \mathrm{~V} \\
\text { 39A D2PAK }\end{array}$ & M6 & Lin Reg FET & 1 & $\$$ & 2.10 & $\$$ & 2.10 \\
\hline 4 & $\begin{array}{c}\text { MMBT5401LT3GOS } \\
\text { CT-ND }\end{array}$ & MMBT5401LT3G & $\begin{array}{c}\text { TRANS PNP 150V 0.5A } \\
\text { SOT-23 }\end{array}$ & Q1-Q5 & PNP switch & 5 & $\$$ & 0.21 & $\$$ & 1.05 \\
\hline 5 & 497-4335-1-ND & STD5N20LT4 & $\begin{array}{c}\text { MOSFET N-CH } 200 V \text { 5A } \\
\text { DPAK }\end{array}$ & M1-M5 & $\begin{array}{c}\text { PNP base } \\
\text { driver }\end{array}$ & 5 & $\$$ & 1.23 & $\$$ & 6.15 \\
\hline 6 & $\begin{array}{c}\text { CBRHDSH1- } \\
\text { 200TR13-CT-ND }\end{array}$ & $\begin{array}{l}\text { CBRHDSH1-200 } \\
\text { TR13 }\end{array}$ & $\begin{array}{c}\text { BRIDGE RECT 1P 200V } \\
\text { 1A 4HD DIP }\end{array}$ & U1 & rectifier & 1 & $\$$ & 1.61 & $\$$ & 1.61 \\
\hline 7 & $\begin{array}{l}\text { SBR1U150SAQ- } \\
\text { 13DICT-ND }\end{array}$ & $\begin{array}{l}\text { SBR1U150SAQ- } \\
13\end{array}$ & $\begin{array}{c}\text { DIODE RECT SBR } 150 \mathrm{~V} \\
1 \mathrm{~A} \text { SMA }\end{array}$ & $\begin{array}{c}\mathrm{D} 1, \mathrm{D} 18, \\
\mathrm{D} 27, \mathrm{D} 32, \\
\text { D35 }\end{array}$ & $\begin{array}{l}\text { cap charge } \\
\text { block diodes }\end{array}$ & 5 & $\$$ & 0.64 & $\$$ & 3.20 \\
\hline 8 & $\begin{array}{l}\text { 3SMAJ5949B- } \\
\text { TPMSCT-ND }\end{array}$ & 3SMAJ5949B-TP & $\begin{array}{c}\text { DIODE ZENER 100V 3W } \\
\text { DO214AC }\end{array}$ & D37 & $\begin{array}{c}\text { 100V zener in } \\
\text { reg }\end{array}$ & 1 & $\$$ & 0.58 & $\$$ & 0.58 \\
\hline 9 & $\begin{array}{c}\text { BZX84C12LT1GOS } \\
\text { CT-ND }\end{array}$ & BZX84C12LT1G & $\begin{array}{l}\text { DIODE ZENER 12V } \\
\text { 250MW SOT23-3 }\end{array}$ & D38 & $\begin{array}{l}\text { 12V zener in } \\
\text { reg }\end{array}$ & 1 & $\$$ & 0.15 & $\$$ & 0.15 \\
\hline 10 & BSR14CT-ND & BSR14 & $\begin{array}{c}\text { TRANS NPN 40V 0.8A } \\
\text { SOT23 }\end{array}$ & Q6 & & 1 & $\$$ & 0.26 & $\$$ & 0.26 \\
\hline 11 & $\begin{array}{l}\text { CRS0805-FX- } \\
\text { 1004ELFCT-ND }\end{array}$ & $\begin{array}{l}\text { CRS0805-FX- } \\
\text { 1004ELF }\end{array}$ & $\begin{array}{c}\text { RES SMD 1M OHM 1\% } \\
\text { 1/4W } 0805\end{array}$ & $\begin{array}{c}\text { R1, R6, } \\
\text { R11, R16, } \\
\text { R21, R27, } \\
\text { R31 }\end{array}$ & & 10 & $\$$ & 0.30 & $\$$ & 2.96 \\
\hline 12 & $\begin{array}{l}\text { RNCP0805FTD10K0 } \\
\text { CT-ND }\end{array}$ & $\begin{array}{l}\text { RNCP0805FTD1 } \\
\text { 0K0 }\end{array}$ & $\begin{array}{l}\text { RES 10K OHM 1\% 1/4W } \\
0805\end{array}$ & $\begin{array}{c}\text { R4, R9, } \\
\text { R14, R19, } \\
\text { R24, R35 }\end{array}$ & & 10 & $\$$ & 0.07 & $\$$ & 0.72 \\
\hline 13 & $\begin{array}{l}\text { RNCP0805FTD4K99 } \\
\text { CT-ND } \\
\end{array}$ & $\begin{array}{l}\text { RNCP0805FTD4 } \\
\text { K99 }\end{array}$ & $\begin{array}{c}\text { RES } 4.99 \mathrm{~K} \text { OHM } 1 \% \\
1 / 4 \mathrm{~W} 0805 \\
\end{array}$ & R34 & & 1 & $\$$ & 0.10 & $\$$ & 0.10 \\
\hline 14 & $\begin{array}{c}\text { RNCP0805FTD90K9 } \\
\text { CT-ND } \\
\end{array}$ & $\begin{array}{c}\text { RNCP0805FTD9 } \\
\text { 0K9 }\end{array}$ & $\begin{array}{c}\text { RES 90.9K OHM 1\% } \\
1 / 4 \mathrm{~W} 0805 \\
\end{array}$ & R30 & & 10 & $\$$ & 0.07 & $\$$ & 0.72 \\
\hline 15 & $\begin{array}{l}\text { RHM220KAEDKR- } \\
\text { ND }\end{array}$ & ESR10EZPF2203 & $\begin{array}{c}\text { RES SMD 220K OHM } \\
1 \% 0.4 \mathrm{~W} 0805\end{array}$ & $\begin{array}{c}R 3, R 8, \\
\text { R13, R18, } \\
\text { R23 }\end{array}$ & & 10 & $\$$ & 0.84 & $\$$ & 8.40 \\
\hline 16 & 541-2852-1-ND & $\begin{array}{c}\text { RCS0805499KFK } \\
\text { EA }\end{array}$ & $\begin{array}{c}\text { RES SMD 499K OHM } \\
1 \% 0.4 \mathrm{~W} 0805\end{array}$ & $\mathrm{R} 29$ & & 1 & $\$$ & 0.27 & $\$$ & 0.27 \\
\hline
\end{tabular}




\begin{tabular}{|c|c|c|c|c|c|c|c|c|c|c|}
\hline 17 & P19275CT-ND & ERJ-6DQF2R0V & $\begin{array}{l}\text { RES SMD } 2 \text { OHM 1\% } \\
\text { 1/2W } 0805\end{array}$ & R33 & $\begin{array}{l}\text { Linear } \\
\text { regulator } \\
\text { resistor }\end{array}$ & 1 & $\$$ & 0.38 & $\$$ & 0.38 \\
\hline 18 & $\begin{array}{c}\text { CSR0805FKR250CT } \\
\text {-ND }\end{array}$ & CSR0805FKR250 & $\begin{array}{c}\text { RES } 0.25 \text { OHM } 1 \% 1 / 4 \mathrm{~W} \\
0805\end{array}$ & $\begin{array}{c}\text { R2, R7, } \\
\text { R12, R17, } \\
\text { R22 }\end{array}$ & $\begin{array}{l}\text { Series sense } \\
\text { resistors }\end{array}$ & 5 & $\$$ & 0.42 & $\$$ & 2.10 \\
\hline 19 & 541-23.2KCCT-ND & $\begin{array}{c}\text { CRCW080523K2 } \\
\text { FKEA }\end{array}$ & $\begin{array}{c}\text { RES SMD 23.2K OHM } \\
1 \% 1 / 8 \mathrm{~W} 0805\end{array}$ & R10 & $\begin{array}{l}\text { comparator } \\
\text { sense } 2\end{array}$ & 1 & $\$$ & 0.10 & $\$$ & 0.10 \\
\hline 20 & 541-11.0KCCT-ND & $\begin{array}{c}\text { CRCW080511K0 } \\
\text { FKEA }\end{array}$ & $\begin{array}{c}\text { RES SMD 11K OHM 1\% } \\
1 / 8 \mathrm{~W} 0805\end{array}$ & R5 & $\begin{array}{l}\text { comparator } \\
\text { sense } 1\end{array}$ & 1 & $\$$ & 0.10 & $\$$ & 0.10 \\
\hline 23 & $\begin{array}{l}\text { RMCF0805FT732KC } \\
\text { T-ND }\end{array}$ & $\begin{array}{c}\text { RMCF0805FT732 } \\
\text { K }\end{array}$ & $\begin{array}{c}\text { RES 732K OHM 1\% } \\
1 / 8 \mathrm{~W} 0805 \\
\end{array}$ & R25 & $\begin{array}{l}\text { comparator } \\
\text { sense } 5\end{array}$ & 2 & $\$$ & 0.10 & $\$$ & 0.20 \\
\hline 24 & BC2853CT-ND & $\begin{array}{c}\text { RCV0805200KFK } \\
\text { EA }\end{array}$ & $\begin{array}{l}\text { RES SMD 200K OHM } \\
1 \% 1 / 8 \mathrm{~W} 0805 \\
\end{array}$ & R28 & & 1 & $\$$ & 0.31 & $\$$ & 0.31 \\
\hline 25 & 1276-1007-1-ND & $\begin{array}{c}\text { CL21F104ZBCN } \\
\text { NNC }\end{array}$ & $\begin{array}{l}\text { CAP CER 0.1UF 50V } \\
\text { Y5V } 0805 \\
\end{array}$ & C3 & & 1 & $\$$ & 0.10 & $\$$ & 0.10 \\
\hline 28 & 36-6095-ND & 6095 & $\begin{array}{l}\text { CONN BANANA JACK } \\
\text { SOLDER LUG }\end{array}$ & J1-J4 & & 4 & $\$$ & 1.38 & $\$$ & 5.52 \\
\hline 29 & 36-4954-ND & 4954 & PC TEST POINT LOOP & J5-J29 & & 25 & $\$$ & 0.20 & $\$$ & 4.90 \\
\hline 30 & 36-9904-ND & 9904 & $\begin{array}{c}\text { MACHINE SCREW PAN } \\
\text { PHILLIPS 6-32 }\end{array}$ & & & 4 & $\$$ & 0.14 & $\$$ & 0.56 \\
\hline 31 & 36-1813-ND & 1813 & $\begin{array}{c}\text { HEX STANDOFF \#6-32 } \\
\text { ALUMINUM 5/8" } \\
\end{array}$ & & & 4 & $\$$ & 0.47 & $\$$ & 1.88 \\
\hline & & & & & & & \multicolumn{2}{|c|}{ Total Price: } & \multicolumn{2}{|c|}{$\$ 59.06$} \\
\hline
\end{tabular}


E. MATLAB Code used for Flicker Index Calculation:

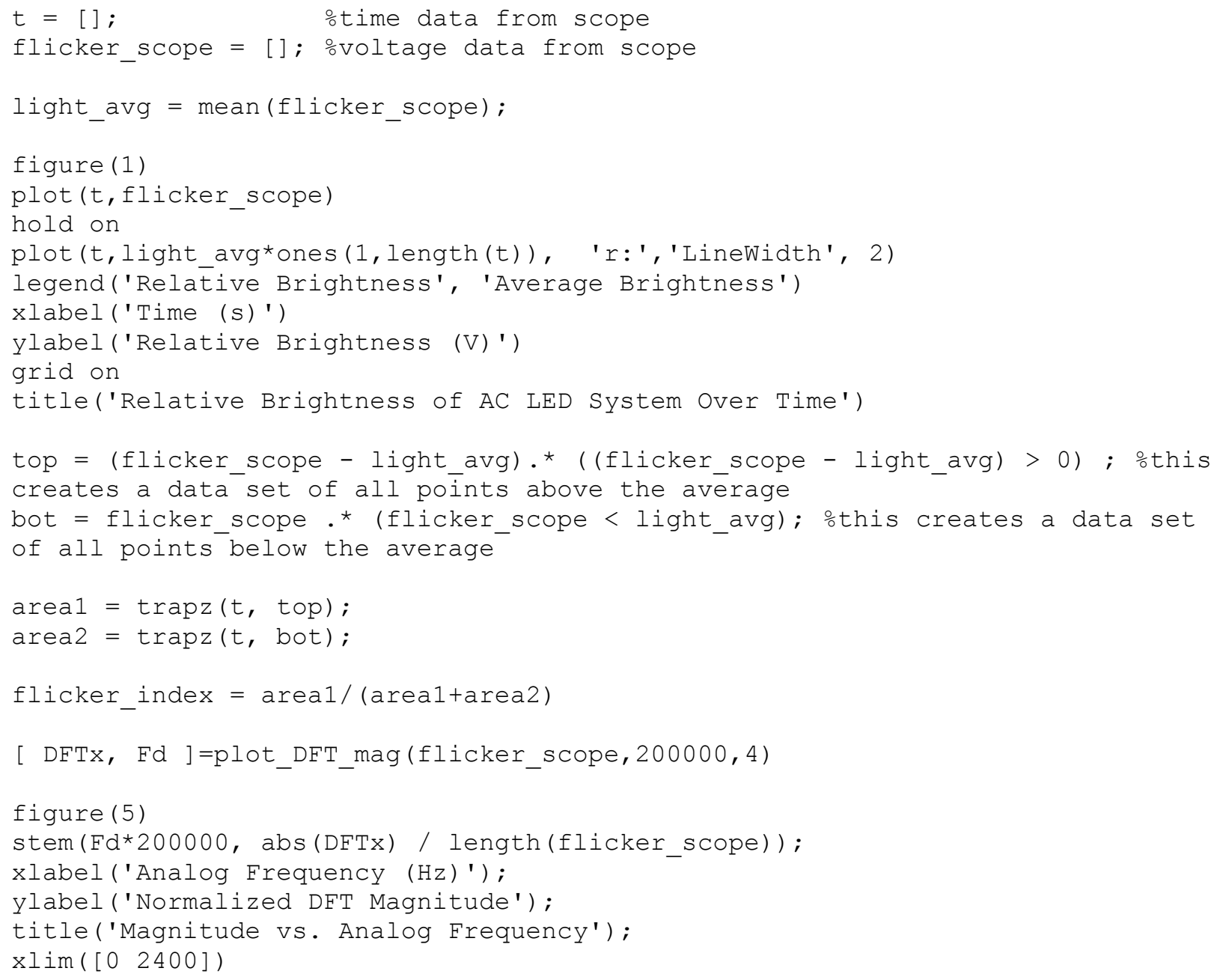

